Journal of Marine Systems

April 2017, Volume 168, Pages 38-56

http://dx.doi.org/10.1016/i.jmarsys.2017.01.003

http://archimer.ifremer.fr/doc/00366/47686/

(C) 2017 Elsevier B.V. All rights reserved.

\title{
Two Decades [1992-2012] of Surface Wind Analyses based on Satellite Scatterometer Observations
}

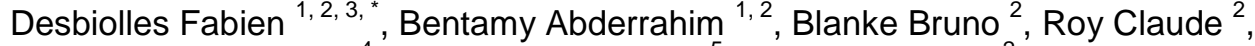 \\ Mestas-Nuñez Alberto M. ${ }^{4}$, Grodsky Semyon A. ${ }^{5}$, Herbette Steven ${ }^{2}$, Cambon Gildas ${ }^{2}$, \\ Maes Christophe ${ }^{2}$
}

${ }^{1}$ Institut Français pour la Recherche et l'Exploitation de la Mer, Plouzané, France

${ }^{2}$ Univ. Brest, CNRS, IRD, Ifremer, Laboratoire d'Océanographie Physique et Spatiale (LOPS), IUEM, 29280, Brest, France

${ }^{3}$ Oceanography Department, MA-RE Institute, University of Cape Town, south africa

${ }^{4}$ Department of Geological Sciences, University of Texas at San Antonio, San Antonio, TX 78249, USA

${ }^{5}$ Department of Atmospheric and Oceanic Science, University of Maryland, College Park, MD 20742, USA

*Corresponding author : Fabien Desbiolles, email address : fabien.desbiolles@uct.ac.za

\begin{abstract}
:
Surface winds (equivalent neutral wind velocities at $10 \mathrm{~m}$ ) from scatterometer missions since 1992 have been used to build up a 20-year climate series. Optimal interpolation and kriging methods have been applied to continuously provide surface wind speed and direction estimates over the global ocean on a regular grid in space and time. The use of other data sources such as radiometer data (SSM/I) and atmospheric wind reanalyses (ERA-Interim) has allowed building a blended product available at $1 / 4^{\circ}$ spatial resolution and every 6 hours from 1992 to 2012. Sampling issues throughout the different missions (ERS-1, ERS-2, QuikSCAT, and ASCAT) and their possible impact on the homogeneity of the gridded product are discussed. In addition, we assess carefully the quality of the blended product in the absence of scatterometer data (1992 to 1999). Data selection experiments show that the description of the surface wind is significantly improved by including the scatterometer winds. The blended winds compare well with buoy winds (1992-2012) and they resolve finer spatial scales than atmospheric reanalyses, which make them suitable for studying air-sea interactions at mesoscale. The seasonal cycle and interannual variability of the product compare well with other long-term wind analyses. The product is used to calculate 20 -year trends in wind speed, as well as in zonal and meridional wind components. These trends show an important asymmetry between the southern and northern hemispheres, which may be an important issue for climate studies.
\end{abstract}

\section{Highlights}

20-year blended of high-resolution $(0.25 \mathrm{deg}, 6 \mathrm{~h})$ wind product from scaterrometry $>$ Blended product suitable for studying air-sea interactions at mesoscale. The product is used to calculate 20-year trends in wind speed, as well as in zonal and meridional wind components. 


\section{Introduction}

A long record of ocean surface wind observations is essential for climate research and for addressing a variety of operational and scientific issues. Surface wind vectors are indeed the key drivers of oceanic and atmospheric processes that regulate the global and regional climate [e.g., Ricciardulli and Wentz, 2013]. Ocean winds are routinely used as the primary forcing function of numerical hydrodynamic models of the ocean circulation [e.g., Grima et al., 1999; Carton and Giese, 2009; Wunsch et al. 2009; Desbiolles et al., 2016] and of surface gravity waves [e.g., Haselman et al., 1988; Tolman 2002] at global and regional scales. Ocean winds are considered as the most important variable for investigating storm surges and wave forecasts at various space and time scales [Debernard et al., 2002]. They drive the variability of ocean processes such as coastal upwelling, primary productivity, cross-shelf transport, deep-water formation, ice transport, and they are of fundamental importance for the reliable estimation of air-sea momentum fluxes (wind stress vector), turbulent heat fluxes (latent and sensible), and gas exchanges (e.g. $\mathrm{CO}_{2}$ and $\mathrm{H}_{2} \mathrm{O}$ ). Longterm change in global winds is an important forcing and an indicator of climate change [e.g. Bourassa et al., 2010].

Ocean surface winds vary rapidly in space and time, as indicated by the omnipresence of small scales in recent scatterometer data [25-100 km of spatial variability, e.g. Chelton et al., 2004]. Some recent studies state that these small-scale features are controlled by sea surface temperature (SST) fronts and their impact on the stratification of the marine atmospheric boundary layer [Beal et al., 1997; see also the review of SST/wind interactions in Small et al., 2008]. Identifying smallscale features in surface wind remains challenging, with dynamic implications for both the ocean and the atmosphere [Risien and Chelton, 2008]. In this respect, satellite-based wind datasets extending over two decades are of considerable interest for many atmospheric and oceanic applications. Wind variations captured by these datasets include both decadal natural variability as well as trends induced by climate change. These long-term variations may be compared to climate model outputs and alternative observations [e.g. Tokinaga and Xie, 2011, Young et al., 2011]. It is 
worth noting that patterns of SST warming simulated by model projections of the future climate are mainly ascribed to wind speed trends [Xie et al., 2010]. Even weak trends can have a substantial impact on atmospheric and ocean dynamics [Yu et al., 2010], air-sea fluxes [Wentz et al., 2007], and the hydrological cycle [Held and Soden, 2006].

Polar-orbiting scatterometers are one of the main sources of surface wind speed and direction over the global ocean. Since the launch of the European Remote Sensing Satellite (ERS-1) in August 1991, a total of 10 independent and successive scatterometer missions have led to improved quality in global observations of wind speed and direction. These missions include the ERS-1 and -2, Quick Scatterometer (QuikSCAT), and Advanced Scatterometer (ASCAT) missions that have been used to produce the blended wind product presented in this paper. Thanks to overlapping periods between these missions, scatterometer winds are continuously available at global scale and span for more than two decades (1992 - present). Today, spatial agencies and meteorological centers deal with space missions involving new scatterometer instruments, aiming at a global fine spatial and temporal resolution ( $25 \mathrm{~km}$ daily, or even $12.5 \mathrm{~km})$. This resolution gets closer to the conditions needed for the accurate derivation of space and time properties of wind-sea interactions. Some key limitations of the satellite wind retrievals are still worth noting such as inadequate temporal sampling of fast atmospheric variability and data contamination by the landocean transition and by the rain, which reduces the overall number of reliable observations.

Many authors have discussed the quality of scatterometer products from each mission [e.g. Quilfen, 1995; Graber et al., 1996; Freilich and Dunbar, 1999, Bentamy et al., 2002; Ebuchi et al., 2002; Bentamy et al., 2008; Verspeek et al., 2010; Sudha and Prasada Rao, 2013] They found that remotely sensed winds are statistically in agreement with in situ measurements (mainly from moored buoys). Creating long consistent time series requires accounting for changes in individual missions, especially when the physics of the measurement (frequency, polarization, instrument geometry) differs from one mission to another [Bentamy et al., 2012]. In addition to the instrument specifications, differences in the direct and inverse methods used for wind retrieval and in the 
spatial and temporal sampling schemes are as numerous as the parameters to be controlled and need to be dealt with in order to reduce errors between the observations. Bentamy et al. [2012; 2013] have highlighted the differences between surface winds retrieved from the ASCAT, QuikSCAT and ERS-2 missions, and Bentamy et al. [2016] have proposed empirical models applied to ERS-1 and 2 backscatter coefficients to calibrate ERS and QuikSCAT wind retrievals and thereby ensure consistency between the missions. The latter study also stresses the necessity for the same Geophysical Model Function (GMF, Cmod5.n [Portabella and Stoffelen, 2009]) to ensure consistency between retrievals determined from the three C-band scatterometers ERS-1, ERS-2, and ASCAT. The application of this method reduces the average global intermission wind differences and the magnitude of their signature at regional scale, in good agreement with in situ buoy-measured winds.

The main purpose of this study is to describe a new 20-year blended wind product available on a regular grid in space (quarter-degree grid spacing) and time (every 6 hours). The present paper is divided as follows. The data we used are presented in Section 2, followed by the description of the objective methods applied to retrieve geophysical fields on a regular grid (Section 3). After the validation of the resulting product, the time consistency of the series is thoroughly discussed

(Section 4). Section 5 presents the new wind product and focuses on its spatial and temporal variability. We finally present the temporal trends for the last two decades for wind speed, and zonal and meridional wind components (Section 6). The paper ends with a discussion of the main findings and with some concluding remarks.

\section{Data}

\subsection{Scatterometer data}

For more than two decades, a sequence of scatterometers on-board polar satellites has been providing a unique quantification of wind vectors over the global ocean from surface roughness 
measurements. Continuous surface wind records are available from ten missions from late 1991 to present. Only four of these missions have been used in this study: C-band (5.3 GHz) scatterometers on-board ERS-1, ERS-2 and METOP-A (ASCAT), and higher frequency Ku-band (13.4 GHz) SeaWinds on-board QuikSCAT (hereafter referred to as QSCAT). The use of these four missions has been motivated by the coverage period (late 1991-present) and by long-standing CERSAT (Centre ERS d'Archivage et de Traitement) expertise in data processing of ERS, QuikSCAT, and ASCAT backscatter measurements.

Briefly, scatterometers are microwave radars that measure ocean wind velocity indirectly through an empirical model linking the wind to the amplitude of capillary or near-capillary surface waves. Indeed, the strength of Bragg scattering or ocean surface radar backscattering $\left({ }^{\sigma_{0}}\right)$, an amplitude directly measured by the radar at a variety of azimuths $(\chi)$, and potentially for multiple frequencies and polarizations, is in equilibrium with the local near-surface wind (relative to the sea surface dynamics). Backscatter measurements allow inference of equivalent neutral wind (ENW) speed $(w)$ and direction $(\phi)$ at 10 m height (i.e., the winds associated with a neutrally stratified atmospheric boundary layer). In particular, the GMF relies non-linearly on ${ }^{\sigma_{0}}$ to estimate $w$ and [e.g. Bentamy et al., 1999; Wentz and Smith, 1999; Portabella and Stoffelen, 2009; Hersbach, 2010]. Level 2 wind retrievals are available on wind vector cell (WVC) grids within the radar ground swath, i.e., suitable areas (depending on radar characteristics) that allow the determination of wind speed and direction for a number of backscatter coefficient measurements. The WVC grid size varies among different wind products between $12.5 \mathrm{~km} \times 12.5 \mathrm{~km}$ (QuikSCAT, ASCAT) and $50 \mathrm{~km} \times 50 \mathrm{~km}($ ERS-1 and -2). Table 1 provides detailed information about each scatterometer, including its operating period, repeat cycle, radar frequency and wavelength. This study employs the swath data (Level2b) of the different missions, as described in Bentamy et al. [2016]. In the latter paper, the authors reprocessed ERS-1 and -2 backscatter measurements to ensure consistency between ERS missions, QuikSCAT, and ASCAT observations. QuikSCAT and ASCAT wind retrievals have been corrected to decrease the inter-mission bias. These adjustments were applied 
specifically to high-latitude Ku-band retrievals from QuikSCAT (SST-related bias correction) and GMF-related bias correction for C-band ASCAT (Bentamy et al. [2011; 2012; 2013] and Grodsky et al. [2012]).

When available (i.e. from July 1999 to October 2009), the new QuikSCAT L2b (known as JPLV3, Fore et al., 2011) is used for the blended product processing and is considered as the reference dataset for statistic calculation and quality control of the new blended winds (see Section 4).

\subsection{Auxiliary datasets}

As explained by Bentamy and Croizé-Fillon [2012] (see their sections 3 and 4) and detailed below (Section 3 of this manuscript), the calculation of gridded winds from sparse scatterometer fields requires the development and use of a method aiming to provide wind vector estimates on regular space and time grids and to reduce the impact of each scatterometer sampling scheme. To improve the analyses at each grid point (i.e., $25 \mathrm{~km}$ spacing every 6 hours) auxiliary information is also used. The selection and the purpose of these datasets are listed below.

Given the repeat cycle of scatterometer missions used in this study (see Table 1) and the expected time frequency of the blended product (6 hours), we use output from atmospheric models to capture the temporal variability of the wind and fill potential gaps in the observational time series. We opted for the ERA-Interim reanalysis of atmospheric parameters produced by the European Center for Medium Weather Forecasts (ECMWF) [Simmons et al., 2006]. It uses 4Dvariational analysis on a spectral grid and spans the period 1989 - present on a fixed $0.75^{\circ}$ grid [Dee et al., 2011]. The fields of the reanalysis used in this study are the zonal and meridional wind components at $10 \mathrm{~m}$ height, available at synoptic times (00:00, 06:00, 12:00, 18:00 UTC).

To enhance the spatial and temporal sampling of surface wind observations required for the blended analyses, we also use wind speed retrievals from the Special Sensor Microwave Imager 
(SSM/I) radiometers on-board the F10, F11, F13, F14, F15 satellites of the Defense Meteorological Satellite Program (DMSP), and from the Special Sensor Microwave Imager Sounder (SSMIS) onboard F16, and F17. Each SSM/I and SSMIS instrument consists of radiometers operating at dual polarizations $(19 \mathrm{H}, 19 \mathrm{~V}, 37 \mathrm{H}, 37 \mathrm{~V}, 85 \mathrm{H}, 85 \mathrm{~V})$ or at a single polarization $(22 \mathrm{~V})$. They provide measurements of brightness temperatures (TB) over the global ocean. Three main geophysical parameters are retrieved from SSM/I TB measurements: column-integrated water vapor content (WV), column-integrated water liquid content (WL), and surface wind speed (wind direction retrievals are not available from SSM/I). Several algorithms for the retrieval of surface wind speed at $10 \mathrm{~m}(\mathrm{~W} 10 \mathrm{~m})$ from SSM/I TB measurements are available [e.g. Schlüssel et al., 1995; Wentz, 1997; Bentamy et al., 1999]. The physical basis relies on the change in surface emission and reflection properties due to the change in roughness forced by the wind stress. In this study, radiometer W10m values are from the latest products, labeled 7, provided by Remote Sensing System (RSS) [Wentz et al., 2012]. These products are assumed to be consistent during the study period (March 1992 - March 2012). Data from F10, F11, F13, F14, F15, and F16 are used for the periods March 1992 - November 1997, December 1991 - May 2000, May 1995 - November 2009, May 1994 - August 2008, December - August 2006, October 2003 - March 2012, and December 2007 - March 2012, respectively. SSM/I and SSMIS wind retrievals are available over a swath of $1400 \mathrm{~km}$, with a WVC grid of $0.25^{\circ} \times 0.25^{\circ}$. No data are available in the presence of rain or for WVC at less than $50 \mathrm{~km}$ from sea ice or land.

Only surface $10 \mathrm{~m}$ wind speeds are retrieved from SSM/I and SSMS TB. The calculation of blended wind products requires the knowledge of wind direction at each SSM/I and SSMS wind cell. Therefore, ERA-Interim wind directions calculated in a window of \pm 3 hours around the SSM/I or SSMIS observation times are trilinearly interpolated in space and time over radiometer swaths. Then, SSM/I and SSMIS zonal and meridional wind components at each cell are estimated from radiometer wind speed retrievals and interpolated ERA-Interim wind directions.

\subsection{Buoy winds}


The surface wind speed and direction obtained from two moored buoy networks are used for validation, and referred to hereafter as in situ references. The first network is maintained by the National Data Buoy Center (NDBC). NDBC buoys are moored off the US coasts, spanning the latitudes from $20^{\circ} \mathrm{N}$ to $65^{\circ} \mathrm{N}$. The second network is operated in the tropics and includes Tropical Atmosphere Ocean (TAO), Prediction and the Research Moored Array in the Atlantic (PIRATA), and the Research Moored Array for African-Asian-Australian Monsoon Analysis and Prediction (RAMA) buoys. TAO, PIRATA, and RAMA buoys are moored in the tropical Pacific, Atlantic, and Indian, respectively and are referred to as tropical buoys (http://www.pmel.noaa.gov/tao/). To provide compatibility with scatterometer winds, the buoy measurements are transformed into Equivalent Neutral Wind (ENW) at standard 10m height using the COARE3.0 algorithm of Fairall et al. [2003]. This algorithm requires the knowledge of SST, air temperature (Ta), and relative humidity (Rh) (or related variables such as specific humidity $\mathrm{q}_{\mathrm{a}}$ ). These parameters are available from the tropical buoys, but only a few NDBC buoys measure air humidity. Therefore, when unavailable, $\mathrm{Rh}$ is set to $80 \%$.

Raw buoy data used in this study are available every 10 minutes or hourly. For comparison with blended winds, all valid buoy data available within 3 hours from the epoch analysis times $(00: 00,06: 00,12: 00,18: 00)$ are arithmetically averaged. The results are referred to as 6-hourly buoy wind estimates.

\section{Methods}

The method used for the estimation of 6-hourly surface wind speed and components is mainly based on the kriging technique with external drift method as described in Bentamy and Croizé-Fillon [2012]. It was developed originally for the calculation of daily-averaged winds from ASCAT scatterometer retrievals. Briefly, the objective method assumes that the estimator of "true" wind (unknown) at each grid point for given synoptic times (00:00, 06:00, 12:00, 18:00) is 
provided by:

$$
\hat{X}_{i}=\frac{1}{t_{b}-t_{a}} \int_{t_{a}}^{t_{b}}\left(\sum_{j=1}^{N} \lambda_{j}\left(X_{o}^{j}\left(x_{j}, y_{j}, t\right)\right)\right) d t
$$

$\hat{X}_{i}$ stands for the wind estimator (zonal, meridional or wind speed, each of which considered as a scalar) at grid point $M_{i}\left(x_{i}, y_{i}\right)$ over the period $\delta t=t_{b}-t_{a}$.

$X_{o}^{j}$ indicates the $\mathrm{j}$-th remotely sensed observation vector available over the satellite swath.

$\lambda_{j}$ is the weighting vector to be estimated. Its determination aims at the minimization of the variance difference between and at each grid point $\left(0.25^{\circ} \times 0.25^{\circ}\right)$ with the following assumptions:

- unbiased constraint $\quad \sum_{j=1}^{N} \lambda_{j}=1$

- external drift constraint $E\left(\hat{X}_{i}\right)=\alpha_{0}+\beta_{1} Y_{i}$

where $Y_{i}$ is the surface wind from ERA-Interim available at the epoch of $M_{i}\left(x_{i}, y_{i}\right)$.

Based on mathematical development (details may be found in Bentamy and Croizé-Fillon [2012]), weight $\lambda_{j}$, and constraint constants $\alpha_{0}$, and $\beta_{1}$ are solutions of a linear system including the spatial and temporal wind structure functions.

More specifically, at grid point ${ }^{M_{i}}$, all valid remotely sensed winds within 6 hours of a synoptic time and at a distance compatible with the spatial structure function characteristics are collected. Data occurring within 3 hours of the synoptic time are used without any modification. The others are temporally interpolated, based on the method described in Bentamy and CroizéFillon [2012], to the start or the end of the analysis period. First, for each hour of the 6-hour period, available scatterometer retrievals are selected. If scatterometer winds are not available or lead to a poor spatial sampling, radiometer winds available for this specific hour are used to enhance the 
spatial and temporal sampling length of observations required for 6-hourly wind estimates at $0.25^{\circ} \times 0.25^{\circ}$ resolution over the global ocean. The sampling length refers to the number of observations in each dataset (i.e., scatterometers or radiometers) used at all steps of the objective method to retrieve wind parameters. Figure 1 shows examples of the mean number of remotely sensed data, available for blended analysis calculations at 00:00 (red color), 06:00 (blue), 12:00 (green), and 18:00 (black) epochs, in January 1994 (top row), 1998 (2nd row), 2002 (3rd row), and 2010 (4th row). They are shown as a function of latitude, from $60^{\circ} \mathrm{S}$ to $60^{\circ} \mathrm{N}$. The results are shown for all satellite data (left column) and for only scatterometer retrievals (right column). As expected, the highest observation numbers are found in the southern ocean, while the lowest are located in the northern oceans due to landmass and ice coverage. The results are very similar at the four analysis epochs, but show significant differences according to the number of satellite instruments available for each specific period. For instance, in January 1994 only ERS-1, F10 and F11 (Figure 1a) are available, whereas QuikSCAT, F13, F14, and F15 (Figure 1e) are used in January 2002. Furthermore, the increased numbers in January 2002 (Figure 1e) and 2010 (Figure 1g) originate from QuikSCAT (Figure 1f) and ASCAT (Figure 1h) sampling schemes. Even if the sampling lengths associated with ERS-1 (Figure 1b) and ERS-2 (Figure 1d) are quite low, they may have a significant impact on the blended wind calculation as a result of the above-mentioned method used for observation selection.

As mentioned above, the objective method uses ERA Interim 10m wind analyses first as external drift (eq. (3)) and for dynamic interpolation of remotely sensed data occurring within a period of 3 hours and 12 hours off the analysis epoch (00:00, 06:00, 12:00, 18:00 UTC) (details are provided in Bentamy and Croizé-Fillon [2012]). The impact of the numerical atmospheric model on the satellite 6-hourly wind analyses is investigated through the use of surface winds derived from the Climate Forecast System Reanalysis (CFSR) model [Saha et al., 2010], instead of ERA Interim. The comparison between the two kinds of satellite 6-hourly estimates, calculated only over short period (months of January 1994, 1998, 2002 and 2010), lead to relatively small differences (not 
shown), not exceeding $0.20 \mathrm{~m} / \mathrm{s}$ for wind speed, and does not show any significant geophysical patterns. Here, the short period of analyses may overestimated mean biases between the two fields.

To assess the impact of the temporal and spatial sampling on the resulting 6-hourly wind analyses (Figure 1), the remotely sensed data are simulated with Climate Forecast System Reanalysis (CFSR) surface winds [Saha et al., 2010]. CFSR zonal and meridional components are bi-linearly interpolated in space and time onto the scatterometer and radiometer swaths selected for the blended wind calculation. The simulated wind speed is calculated as the magnitude of the interpolated components. Simulated satellite winds are then used as observations for the calculation of 6-hourly wind fields based on the objective method presented above (Eqs. 1 through 3). The resulting blended winds are compared to the original 6-hourly CFSR analyses. Figure 2 shows the spatial distributions of the mean (bias) and standard deviation (STD) difference and correlation coefficient linking the original and reconstructed wind speed fields. They are estimated from 6hourly datasets calculated in January 1994, 1998, 2002, and 2010. The mean differences between the original and reconstructed wind speeds are quite small for the four periods (Figures $2 \mathrm{a}, 2 \mathrm{~d}, 2 \mathrm{~g}$ and $2 \mathrm{j}$ ). The mean and median biases of each dataset do not exceed $0.10 \mathrm{~m} / \mathrm{s}$. The lowest values are found in January 2002 and 2010, whereas the highest values are found in January 1994. For instance, bias values exceeding $0.50 \mathrm{~m} / \mathrm{s}$ are obtained along the equator in January 1994. This is the combination of a sampling length issue and wind variability. Indeed, wind speed in January 1994 has larger variability than, for instance, in January 2002 (not shown).

Finally, it should be emphasized that our data merging procedure is different from conventional optimal interpolation. It employs only the temporal variability inferred from the common background (ERA-Interim) to fill remaining gaps in the Level 2 data. This method has the advantage not to disrupt the wind retrieval at the time of the satellite measurements, allowing to remain as close as possible to the scatterometer data. The use of ERA-Interim is then justified by the need of 6-hour outputs, and the high-frequency temporal variability of the blended product is then ascribed by the reanalysis. This procedure, for the most part, preserves the long-term 
variations of the observations in the analyzed fields. Hence, the long-term variations of the analysis are not predefined by the long-term variations of the background.

\section{Validation}

\subsection{Potential errors due to the sampling scheme}

In this section, we evaluate the potential errors due to the heterogeneity of sampling across the different missions. Indeed, the sampling of the global ocean has been improved over time and missions. Furthermore, parameters such as the geometry and cycle of each instrument have been designed separately by different agencies (see Table 1). If differences between QSCAT and ASCAT are not meaningful in terms of sampling and repeated cycle, the consistency in the wind retrieval scheme between ERS-1 (-2) and QSCAT can be a core issue for the blended product.

As a sensitivity test, we generated two wind products for December 1999 when ERS-2 and QuikSCAT data are available. The first product is constructed by using all available data, while the second one is constructed by excluding QuikSCAT (indicated as blended-ERS). The comparison of the two datasets and of the ERA-Interim wind field with QSCAT L2 data allows us to control the quality of the blended product in the absence of QSCAT data (1991 to 1999). Figure 3 shows the RMSE (Root Mean Square Error) in December 1999 between QSCAT L2 data considered here as a reference and the blended product incorporating all the data (top row), the blended-ERS product (middle row) and ERA-Interim reanalyzes (bottom row). Wind speed, and $\mathrm{u}$ and $\mathrm{v}$ components are analyzed separately and presented in the 1st, 2nd and last column of Figure 3, respectively. It must be noted that QSCAT L2 data have been averaged on the regular grid of the blended product to compute the RMSE: between 30 and 100 QSCAT values are available on each grid point in December 1999 (not shown), which results in valid statistics. There is general agreement about the relevance of QSCAT data for the study of wind fine-scale variability (cf. Chelton et al., [2004]). 
Therefore, QSCAT L2 data are considered in this section as a reference. Moreover, the comparison between the different products designed for this sensitivity experiment allows us to evaluate the relative error associated with some components of the blended product (e.g., ERA-Interim vs. QSCAT L2 data).

Not surprisingly, the product constructed with all the data presents the lowest RMSE for all the variables presented (i.e., wind speed, $\mathrm{u}$ and $\mathrm{v}$ components). The largest RMSEs are found in the northern hemisphere for both the Atlantic and Pacific oceans. This was not unexpected because the statistics are calculated during the boreal winter (in December) when numerous storms develop, notably in the northern Atlantic [Tokinag and Xie, 2011]. The Gulf Stream region presents important RMSEs for all the products presented here, and this result can be ascribed to the fewer number of QSCAT observations in December 99 ( 30, not shown). The two blended products (with or without inclusion of QSCAT data) show better statistics than ERA-Interim. This is notably true for the wind speed (Figure 3, first column). The mean wind speed differences between QSCAT L2 and blended-ERS tend to be lower than those related to the differences between QSCAT L2 and ERA-Interim. For instance, it is found that blended-ERS leads to better results than ERA-Interim in the western Atlantic Ocean and at high latitudes. RMSEs dealing with zonal and meridional wind components calculated either between blended-ERS and QSCAT L2 data or between ERA-Interim and QSCAT L2 data are substantially equivalent (Figure 3, second and third rows). As stated in section 2.2, SSM/I wind components are supplemented by information extracted from ERA-Interim for the calculation of wind directions, especially during the ERS period. Therefore, it is expected that ERA-Interim and the blended product constructed with only ERS2 data are statistically equivalent for the wind direction. However, we have previously shown that the wind speed is significantly improved through inclusion of both SSM/I and ERS-2 data. 


\subsection{Comparison with buoys}

To assess the quality of the satellite wind analyses, 6-hourly blended and buoy wind estimates available for the same synoptic time are spatially collocated using the nearest neighbor approach based on a $25 \mathrm{~km}$ distance criterion. The spatial and temporal collocation is performed for all the NDBC buoys, including the coastal moorings, and the Tropical buoys for the period 1992 2012. The numbers of observations of collocated data for the whole period are 1655821 and 1387000, for the NDBC and Tropical comparisons, respectively. They show significant space and time contrasts. For instance, the numbers of collocated data associated with Tropical moorings for the periods March 1992 - June 1999 and July 1999 - October 2006 account for 24\% and 42\% of the total, respectively. Quite similar results are found for the collocated sampling lengths in the NDBC comparison. Moreover, further investigations need to be performed in tropical areas for satellite wind field analyses occurring after 1999, and especially after 2007 when moorings are available for the three tropical oceanic basins. Prior to 1999, the comparisons between tropical and satellite 6-hourly wind estimates are only performed in the Pacific area.

The accuracy of the blended wind analyses is first characterized by the first statistical moments of their differences with collocated buoy data. For the NDBC comparison, the statistics are estimated for the moorings located offshore (>50 km from the shoreline) and at nearshore sites. They are summarized in Table $\mathbf{2}$ and Table 3. The tables also show the statistics (within brackets) based on the comparison between buoy and ERA-Interim winds. All the statistics are significant since the order of magnitude of the minimum of observations (collocated data) is 9000 . For the offshore comparison (Table 2), the overall mean difference (bias) between buoy and satellite wind speeds is quite small, and the associated standard deviation (STD) is about $1 \mathrm{~m} / \mathrm{s}$. Although the wind direction bias is small, it indicates that the directions of the blended winds are slightly rotated anticlockwise compared to buoy data. The STD of the wind direction difference is lower than $20^{\circ}$, showing the good agreement between the wind directions of different sources. The fair agreement 
between NDBC and blended wind, both for speed and direction, is also confirmed by scalar correlation ( $r^{2}=0.96$ ), symmetrical linear regression coefficient ( $b s=0.97$ ) for only the wind speed, and by vector correlation ( $\rho^{2}=1.90$ ) for wind direction. The statistics estimated for the four selected periods are of the same order as those calculated for the whole time series. They do not indicate any systematic departure associated with the use of scatterometer data in blended wind calculations. Furthermore, the statistics show a better agreement between NDBC and blended wind speeds than between NDBC and ERA-Interim winds (Table 2). For wind direction, the comparisons for blended winds and ERA-Interim winds are very similar. This result is partly due to the attribution of the ERA-Interim wind direction to the SSM/I wind cells (see Section 4.1).

The statistics about accuracy are poorer for the nearshore sites (Table 3) than for the offshore buoys. The blended wind speeds tend to be systematically underestimated. The mean differences between buoy and blended wind data, calculated for all selected periods, vary between $0.41 \mathrm{~m} / \mathrm{s}$ and $0.74 \mathrm{~m} / \mathrm{s}$. The lowest biases are obtained over the QuikSCAT (1999-2009) and ASCAT (20072012) periods. These two scatterometers provide WVC retrievals with higher resolution $\left(0.125^{\circ} \times 0.125^{\circ}\right.$ and $0.25^{\circ} \times 0.25^{\circ}$, respectively $)$, even near the coast. The results of the comparison, of course, highly depend on the distribution of remotely sensed winds along the coastal areas [Stiles, 2014] where they are limited in number. The auxiliary ERA-Interim surface wind used in the objective method with a no drift constraint may here have a significant impact on the blended estimates [Bentamy et al., 2012]. Nevertheless, the nearshore blended winds show a good agreement with buoy data in terms of root mean square (RMS) difference, lower than $2 \mathrm{~m} / \mathrm{s}$, and correlation and symmetrical coefficients, about 0.90 . These statistics indicate a significant improvement in nearshore wind speed estimation over the ERA-Interim results.

The accuracy of the blended wind speed and direction is also investigated through comprehensive comparisons with 6-hourly averaged Tropical buoy data. The results are shown in Table 4. The statistics are similar to those obtained for NDBC comparisons. The symmetrical regression and correlation coefficients exceed 0.97 and 0.91 , respectively, assessing the good 
agreement between buoy and blended wind speeds. The RMS wind speed differences, estimated from bias and STD values, are lower than $1 \mathrm{~m} / \mathrm{s}$. Furthermore, the surface wind speeds from blended data compare better to buoy data than the ERA-Interim winds (Table 4). For the wind direction, the blended and ERA-Interim wind products lead to similar comparison results. For the two products, the wind direction biases and STD do not exceed $17^{\circ}$. Although the correlation coefficients for the wind direction vector are quite high $(>1.70)$, they are slightly lower than those obtained in the NDBC comparison (>1.90) (Table 1). This is mainly due to the difference between the wind speed distributions derived from the NDBC and tropical buoy data. For instance, across the Atlantic and eastern Pacific equatorial mooring locations, where light winds $(<5 \mathrm{~m} / \mathrm{s})$ are persistent, the vector correlation coefficients are lower than 1.43. Previous studies indeed showed that scatterometer wind directions are less accurate for low wind speed conditions (e.g. Bentamy et al. [2008]).

Additional accuracy tests are performed as a function of time and according to some selected atmospheric and oceanic conditions. Figure 4 shows the time series of monthly mean and STD difference between offshore NDBC and blended 6-hourly wind estimates, the associated correlation coefficient, and the sampling length of data used for monthly calculations. The results are shown for the whole study period (March 1992 - March 2012). Wind speed bias values (Figure 4a) do not exceed $0.30 \mathrm{~m} / \mathrm{s}$, and more than $90 \%$ of the values are less than $0.20 \mathrm{~m} / \mathrm{s}$. Similar results are found for the zonal and meridional biases excepted for short period during when an important bias is captured $(>0.4 \mathrm{~m} / \mathrm{s})$. These peaks can be explained by important local mean biases between buoys and the blended product (not shown). Although biases are large and then influence general statistics presented here, they concern only specific locations during limited time period. The STD differences (Figure 4b) for the wind speed and for the associated components are lower than 1.20 $\mathrm{m} / \mathrm{s}$ and $2 \mathrm{~m} / \mathrm{s}$, respectively. Wind speed difference STDs are quite consistent during the study period, while difference STDs related to the zonal and meridional components tend to be slightly higher during the period 1992-2000 compared to 2000-2012. This is partly due to the change in 
sampling length (Figure 4d), and especially the use of QuikSCAT and ASCAT wind directions for the blended calculations. Time series of scalar correlation coefficients assess the good agreement between buoy and blended winds during the whole period. The three correlation coefficients (Figure 4c) exceed 0.95 most of the time.

\section{Spatial and temporal variability of the blended wind product at global scale and over key oceanic regions}

\subsection{Spatial variability of the wind and its derived fields}

We acknowledge that the construction and the distribution of a 20-year-long surface wind product at 6-hourly and $1 / 4^{\circ}$ resolution are ambitious, and that the necessary use of auxiliary data can affect the richness of spatial scales of the different missions. This section presents some analyses of the blended product and its derived fields. We compare them to the ERA-Interim and QSCAT products, respectively. Some results are shown over the global ocean, and we also focus on Southern Africa to analyze some regional features. This complex area shows strong air-sea interactions and pronounced dynamic features (Agulhas region [O'Neill et al., 2005], Benguela upwelling system [Desbiolles et al., 2014b], Angola-Benguela frontal zone [Colberg and Reason, 2007]).

Figure 5a gives an example of the blended wind analysis for a specific day (15 December 1999, the 4 epochs of the day being averaged) that could be compared to daily-averaged ERAInterim data and QuikSCAT (Figures 5b and 5c, respectively). For clarity, only the wind speeds larger than $10 \mathrm{~m} / \mathrm{s}$ are drawn as vectors. The curl (top panels) and divergence (bottom panel) of the wind are shown in Figure 6. In the light of the statistical comparisons presented in the former 
section, equivalent characteristics can be expected between the different fields. In terms of wind speed and direction (Figure 5), the blended product shows the same synoptic patterns as QuikSCAT daily winds. The large cyclonic circulations over both the North Atlantic and North Pacific are slightly more pronounced in the QuikSCAT fields. The Southern Ocean shows intense westerlies, and the area characterized by winds higher than $10 \mathrm{~m} / \mathrm{s}$ is slightly larger in the blended winds than QuikSCAT alone. For all the patterns described above, the ERA-Interim winds are the least intense and this is also the case for the Atlantic trade winds. ERA-Interim winds also show less acute spatial patterns, as highlighted by the derived fields presented in Figure 6. The QuikSCAT wind curl and divergence present undoubtedly smaller-scale features on this specific day, but the blended product significantly improves the wind curl and wind divergence descriptions in comparison with ERA-Interim (Figures $6 \mathrm{c}$ and $6 \mathrm{f}$ ). In terms of richness of spatial scales, the blended product shows substantial improvements over ERA-Interim especially in the Brazil-Malvinas confluence, the Agulhas region and the Northern Atlantic and Northern Pacific (where large cyclonic circulations can be identified, see Figure 5).

As an example of small-scale features, Figure 7a shows wind speed perturbations in color and SST perturbations in contours on 15 December 1999, around the Agulhas and Benguela upwelling systems. Following O'Neill et al. [2005], the perturbation fields are defined as the spatially high-pass filtered fields (for both blended wind speed and SST, here the so-called Reynolds product - Reynolds et al. [2007]). These fields are obtained by first isolating large-scale features by applying a Lanczos filter with half-power filter cutoff wavelengths of $10^{\circ}$ both in latitude and longitude. The spatially high-pass filtered fields were then obtained by subtracting the Lanczos smoothed fields from the unsmoothed SST and wind speed. High spatial positive correlations are found between the SST and wind perturbations off Southern Africa for the year 1999 (not shown). Despite the use of the Reynolds SST, for which feedback processes can be significantly underestimated because of the coarse spatial resolution of the SST analysis [O'Neill et al., 2005], Figure 7a highlights a strong correspondence between SST and wind perturbations. This 
result confirms that SST exerts an influence on the surface wind, consistently with the observations reported by O'Neill et al., [2005] for the Agulhas region and Desbiolles et al. [2014b] in the Benguela upwelling region. This is especially the case over Agulhas rings, but also over the upwelling SST front. Therefore, the blended wind product includes the spatial scales needed for the study of thermal feedback on atmospheric flows. This is confirmed by the binned scatter plot over 1999 of the 15-day running averages of the SST and wind speed perturbations (Figure 7b). The slope of the linear regression is $0.1976[\mathrm{~m} / \mathrm{s}] /{ }^{\circ} \mathrm{C}$, which is consistent the study of Chelton et al. [2004].

To supplement adequately the presentation of the spatial scales of the blended winds, we computed wave number spectra over the global ocean in December 1999 (Figure 8). The spectra for ERA-Interim and QuikSCAT and the theoretical $\mathrm{k}^{-2}$ and $\mathrm{k}^{-4}$ profiles are also shown for comparison. Indeed, the effective resolution of satellite observations and model fields can be quantified from a wavenumber spectral analysis (e.g., Milliff et al. [2004]; Chelton et al. [2006]; Lefevre et al. [2010]). The spectra for the wind speed and its two scalar components show approximately equivalent behavior for wavelengths higher than $1000 \mathrm{~km}$. Wavenumber spectra for the wind speed show a sharp change at about $150 \mathrm{~km}$ and $100 \mathrm{~km}$ for ERA-Interim and blended wind speeds, respectively (dashed and bold lines in Figure 8). These abrupt modifications correspond to their related effective resolution, which is about 4 grid spacings for each product. The differences between the ERA-Interim and blended wind wave number spectra are more obvious when focusing on the zonal and meridional components. The effective resolution of the blended wind proves consistent with the scales required for the study of mesoscale air-sea coupling (see Figures $7 \mathrm{a}$ and $7 \mathrm{~b}$ ).

\subsection{Temporal variability}




\subsubsection{Diurnal cycle and day-to-day variability}

The diurnal cycle and the day-to-day variability of ocean winds can be substantial [Bourassa et al., 2010]. The blended product is composed of 4 samples per day, from 1992 to 2012. We have seen that the different missions do not cover the entire period equally, but auxiliary data, and especially SSM/I radiometers, regulate the number of observations throughout the entire period to ensure the adequate numbers of satellite measurements and generate valid wind estimates. Figure 9 shows the mean bias of the day-night difference from ERA-Interim and blended winds averaged during 1999. The differences are almost positive everywhere in both products (not shown) and the differences between the two products are more important at mid- and high-latitudes for both mean values (color) and standard deviation (contours). That can be explained by the sampling scheme of polar satellites (SSM/I, ERS2 and QuikSCAT): At low latitudes, the diurnal cycle is essentially controlled by the model while at higher latitude the analysis takes full advantage of the repeat cycle of QuikSCAT originally, and SSM/I to a lesser extent. As a side note, it is important to mention that the day-to-day variability is higher in the blended product than in the ERA-Interim field (not shown).

\subsubsection{Seasonal variability}

Figure 10 shows both the boreal winter (DJF) and summer (JJA) long-term wind speed and wind vector averages over the 20-year blended analysis and Figure 11 shows similar fields for the wind curl and wind divergence. The expected seasonal cycles can be found in the blended product, with both large mean and standard deviation (black contours in Figure 10) in the northern (southern) hemisphere during boreal (austral) winter. This is especially the case in the Gulf Stream and Kuroshio regions where numerous winter storms drive the large seasonal variability [Tokinaga and Xie, 2011]. This is also true in the southern hemisphere with strong westerlies south of $30^{\circ} \mathrm{S}$ during boreal winter. Trade winds usually show a large seasonal cycle, with the peak season in 
local winter, but can also persist throughout the year in regions such as the Eastern Pacific (see Figure 10). Figure 10 shows clearly the northward migration of the South Atlantic subtropical high during boreal winter (DJF), which leads to large upwelling-favorable winds in the Benguela upwelling system. The Indian Ocean shows the strongest seasonal variability associated with the monsoon cycle: dominant winds turn from northeasterly in boreal winter to southwesterly in summer [Schott and McCreary, 2001], which leads to seasonal coastal upwelling processes. This change is mainly forced by the migration of the Intertropical Convergence Zone (ITCZ) visible on the seasonal average of the wind divergence (Figures $11 \mathrm{c}$ and 11d). In the Indian Ocean, this migration reaches $10-15^{\circ} \mathrm{S}$ and $25-30^{\circ} \mathrm{N}$ during the DJF and JJA season, respectively. The monsoon cycle, with northerly winds from December to March and southerly winds from May to September develops in between [Schott and McCreary, 2001]. The rest of the intertropical band is also characterized by the migration of the ITCZ (Figure 11). The wind curl also shows large seasonal variability, especially in the equatorial ocean. The blended product captures well the annual cycle of wind speed and direction, wind curl and divergence of the mid-latitude westerlies and trade winds over the Pacific and Atlantic Oceans.

\subsubsection{Annual to interannual variability, spectral analysis}

Figure 12 shows the power spectra of monthly-averaged zonal (dashed lines) and meridional wind components (thick lines with stars) as well as wind speed (bold lines), spatially averaged over the northern Pacific and Atlantic oceans (Figures 12a and 12b, respectively), over the eastern equatorial Pacific (Figure 12c), and over the Indian Ocean (Figure 12d). As stated earlier, the semiannual cycle is important in the four basins, with a well-identified energy peak at two cycles per year (Figure 12), and so is the annual cycle. More interestingly, lower frequency variability can be found in the four areas but with different periods: 4 and 3 years in the northern Pacific and Atlantic, respectively and 6.5 years in both the eastern equatorial Pacific and the Indian Ocean. The latter period corresponds approximately to ENSO (El Niño-Southern Oscillation) variability, which is 
clearly visible in the zonal wind component (Figures 12c and 12d). This result confirms the ENSO imprint on wind variability (for its speed and scalar components), previously highlighted from monthly satellite-derived latent heat fluxes in the eastern Pacific [Mestas-Nuñez et al., 2013]. An ENSO-like variability is also found in the Indian Ocean with the same period of oscillation (Figure 12d), which confirms a connection between the equatorial Pacific and the Indian Ocean and the propagation of ENSO signals to the Indian Ocean [Reason et al., 2000].

\section{Wind trends over the past two decades}

Another strength of the present analyses is the calculation of long-term trends in wind speed, and in zonal and meridional components. Specifically, we study the trend over the last two decades and its implications on wind-derived fields. The linear trends have been performed by using the least squares linear regression fit to the data. The significance of the trends is estimated from Monte-Carlo tests.

Figures 13a and 13b show for comparison the scalar wind trends for the blended winds and ERA-Interim, respectively. Trend values with significance lower than $80 \%$ are plotted with shaded colors. As explained by Tokinaga and Xie [2011], the scalar mean wind speed is slightly different from the magnitude of the mean wind vector. This difference comes from unsteadiness in wind direction. The trends of the zonal and meridional wind components of the blended product are shown in Figures 14a and 14b, respectively. Blended winds show negative trends in the subtropical North Atlantic of the same order as those found for ERA-Interim, or in the WASWind product [see Figure 15 of Tokinaga and Xie, 2011]. It should be noted that the QuikSCAT wind trends (calculated through the 1999-2009 period) do not appear as significant as those calculated from longer time series of the blended winds or ERA-Interim, but also show negative values in the North Atlantic and North Pacific (not shown). In contrast with the open ocean, the western coast of North America south of the Gulf of Alaska is characterized by a significant positive trend in wind 
speed (Figure 13). This wind speed trend is associated with a significant increase in upwellingfavorable winds off the Oregon coast (Figure 14b). Furthermore, among the four largest coastal upwelling regions (i.e., California, Peru, Canary and Benguela), the largest positive trends in upwelling-favorable winds are seen in the California system. It is worth mentioning here that the ERA-interim wind speed presents a negative trend in the southern part of the northern America upwelling system (along the South California and Baja California coast). The northern part of the Canary system also shows a large negative trend in the meridional wind component (corresponding to an increase in upwelling-favorable winds). The Benguela system is characterized by opposite trends in its northern and southern regions: the northern Benguela upwelling system presents positive trends, mainly along the coast of Namibia, while the southern system shows a very small region of negative trends close to the coast (Figure 14b). At low latitudes and for the zonal wind component, the coastal regions of the Indian Ocean show significant positive trends, and the pattern of positive trends extends further south in the Mozambique Channel and the Agulhas region (Figure 14a). The equatorial and subtropical regions show the largest positive trends in wind speed, except in the mid-Indian Ocean where negative trend is visible (Figure 13). The equatorial Pacific is characterized by a noteworthy increase of the trade winds (Figures 13 and 14a). The southern hemisphere generally shows more positive than negative wind speed trend values (Figure 13a).

Figure 15a shows the zonally averaged significant wind speed trends for the blended winds (black line) and ERA-Interim (grey line) as a function of latitude. Figure 15b itemizes the zonally averaged trends of the blended wind speed (solid line), as well as the blended zonal and meridional components (dashed and dotted lines respectively) as a function of latitude, for the Pacific, Atlantic, Indian and Southern Oceans. There is a very pronounced asymmetry between the northern and southern hemispheres in the two products. While the northern westerlies show a strong negative trend, their southern equivalents are characterized by slightly positive values. The negative trend in the northern westerlies is particularly strong around $40^{\circ} \mathrm{N}$. This substantial decrease is notably due to the reduction of the zonal component in both the Pacific and Atlantic basins, from $35^{\circ} \mathrm{N}$ to $65^{\circ} \mathrm{N}$ 
in the Atlantic Ocean, and only from $30^{\circ} \mathrm{N}$ to $50^{\circ} \mathrm{N}$ in the Pacific (Figure $15 \mathrm{~b}$ ). Trends in trade winds also show contrasts between the two hemispheres, with more intensification in the southern winds (Figure 15a). This is especially true over the Atlantic Ocean where northern trade winds admit some negative trends. The Pacific Equatorial region is characterized by an important increase of the wind, particularly influenced by the zonal component (Figure 15b, see also Figure 14a). The Southern Ocean is characterized by a positive trend, however less important than expected from the strengthening of the Southern Annular Mode index. The Indian Ocean presents a fairly noisy signal.

The above asymmetry has already been noted and commented by several authors [e.g., Xie and Philander, 1994; Tokinaga and Xie, 2011] and can be of prime importance for wind-related quantities such as turbulent heat fluxes, and especially for evaporation in the northern Atlantic as a result of the reduction of northern hemisphere westerlies.

\section{Discussion and concluding remarks}

This paper presents a new multiyear wind product based on scatterometer retrievals from 4 different missions since 1992 (ERS1, ERS2, QuikSCAT, and ASCAT). It also uses SSM/I wind retrievals and ERA-Interim data to avoid sampling errors of the different missions and is therefore called a blended product. This blended wind product is based on the homogenization of backscatter coefficients between ERS1/2 and QuikSCAT [Bentamy et al., 2016] and is available over the period 1992-2012, with a temporal resolution of 6 hours and a spatial resolution of $0.25^{\circ}$ both in latitude and longitude. As explained in detail in Section 3, the method is based on a kriging technique and employs all valid remotely sensed winds within 6 hours of a synoptic time and at a distance compatible with the spatial structure function characteristics. Additional data are used to enhance the spatial and temporal sampling of observations required to generate 6-hourly wind estimates in a $0.25^{\circ} \times 0.25^{\circ}$ latitude-longitude grid over the global ocean. 
Careful attention was paid to potential errors due to the sampling scheme of each mission, and especially between the two ERS missions (ERS1 and ERS2 were designed in an equivalent manner) and QuikSCAT. For this purpose, scatterometer data (i.e., ERS-2 and QuikSCAT) were included in the processing, first separately and then together, to define two wind products in December 1999 when both ERS-2 and QuikSCAT data were available. Potential discontinuities inherent in the inclusion of QuikSCAT data in the procedure are then carefully checked. The comparison of the two datasets and of the ERA-Interim wind field with QSCAT L2 data allows controlling the quality of the blended product in the absence of QSCAT data (1991 to 1999). We have shown that the product constructed with all the data presents the lowest RMSE for all the variables presented (i.e., wind speed, $\mathrm{u}$ and v components, see Figure 3). The two blended products (with or without inclusion of QSCAT data) show improved statistics versus ERA-Interim. A third product has been computed to complete this sensitivity experiment. This product uses only radiometer data and the ERA-Interim reanalysis (blended-SSM/I). It shows quite similar statistics as those obtained by blended-ERS, both improving statistics in comparison with ERA-Interim reanalysis. This result is consistent with the fact that SSM/I data contribute significantly to the blended estimates during 1991-1999 due to sparse ERS data (both ERS-1 and -2), unlike during the QSCAT period (Figure 1). An important point to consider is that the blended-SSM/I and the blended product constructed with ERS2 data only are statistically equivalent for the wind direction. Indeed, wind direction information is extracted from ERA-Interim during the period 1991-1999. We also showed a wind analysis for a specific day (Figures 5 and 6). Specifically, daily means of the blended wind and derived fields (wind curl and divergence) compared well with equivalent information inferred from daily QuikSCAT data.

The blended product has been validated through comparison with buoy data. Buoy-measured and satellite-retrieved winds are not precisely equivalent, but a careful filter applied to buoy data and a conversion to equivalent 10-meter winds allowed a direct comparison knowing that such validation has already been performed [e.g., Bentamy et al., 2012; 2016]. We found that all the 
statistics between blended winds and buoys are in better agreement than those calculated with ERA-Interim, independent of the period chosen in the entire time series.

After validation, we have described the spectral content of the new wind product in time and space. The perturbations of the wind field match patterns of SST perturbations in the oceanic region off Southern Africa (see Figure 7a). This region has been already described as a hot spot to study air-sea interactions at the mesoscale. A linear relationship between the two fields has been found over the Agulhas region (Figure 7b), with a coupling coefficient equivalent to that of other studies [O'Neill et al., 2005; Chelton et al., 2004]. Therefore, the blended data include spatial scales that are coherent with the scales of coupled thermodynamic processes between the wind and SST (on the order of $100 \mathrm{~km}$ ). This was confirmed by wave number spectra calculated for the wind speed and its zonal and meridional components (Figure 8). Hence, we have established the effective spatial resolution of the blended product to be about 4 grid spacings $(100 \mathrm{~km})$, which is finer than the atmospheric reanalyses.

The temporal variability of the blended product has also been analyzed, from diurnal to decadal scales. As noted by Bourassa et al. [2010], the diurnal cycle of ocean winds can be linked to cloud formation and it is of particular interest for ocean forcing (mixing and air/sea fluxes). For example, Lee et al. [2008] showed that the mixed layer they simulate with an ocean model is increased when using winds with a fully resolved diurnal cycle in contrast to wind data smoothed over 24 hours. This can lead to $1^{\circ} \mathrm{C}$ colder SST over a season. Satellite sampling is still inadequate for diurnal studies but our approach, which consists of the combination of satellite observations and atmospheric model data, leads to greater differences in day-night winds at mid- and high-latitudes than those found in ERA-Interim (see Figure 9). There is every reason to believe that the analysis at mid- and high-latitudes fully exploits the fact that every Wind Vector Cell is sampled twice a day during the QuikSCAT and ASCAT period. The blended product reproduces the main features of the seasonal variability in wind speed and direction, as illustrated by wind curl and divergence (see Figures 10 and 11). The interannual variability and other variations at lower frequency seem to be 
linked to signals like ENSO in the Equatorial Pacific (Figure 12).

Trend calculations have been performed with increasing and decreasing intensities in the blended winds generally matching the findings of Tokinaga and Xie [2011]. Blended trends are also of the same order of magnitude as trends in ERA-Interim and QuikSCAT. An important asymmetry is found between the two hemispheres (see Figure 15). This result has been already commented (e.g., Xie and Philander [1994]; Tokinaga and Xie [2011]) and could have a primary importance in climate change scenarios. For example, and as remained by Xie and Philander [1994], a weakening (strengthening) of the northeast (southeast) trade winds increases (reduces) SST warming in the northern (southern) subtropical Pacific through wind-evaporation-SST feedback. The most important negative trends found in the blended winds are found in the northern westerlies in both Pacific and Atlantic basins (see Figure 15b). This negative trend in westerlies can modify evaporation in the North Atlantic, and thus impact the thermohaline circulation. This is why we are currently working on the construction of blended turbulent heat fluxes associated with these blended winds.

The interpretation of wind trends is challenging because of the relative short period of analysis (two decades) and because wind data are strongly influenced by near-decadal variability (see Section 5). This effort, as well as those of other scientific teams, may show divergent wind trends that depend on measurement techniques. In particular, wind retrievals from historical wave observations [Beaufort scale, see Tokinaga and Xie, 2011] are very different if altimeter based instrumental wave data are used in their processing [Young et al., 2011]. In this paper, we have presented a trend analysis of the blended and ERA-Interim products with the obvious drawback that the latter product is used in the blended product as auxiliary data. We have compared the trends of the two products although they cannot be considered as entirely independent (the weight of ERAInterim in the final wind estimate has not been fully quantified). Despite some local discrepancies, the two trends present the same large-scale patterns (see Figure 13). Moreover, the blended product shares many common large-scale features (both in wind speed and components) with the trends 
calculated with the 20CR reanalysis (http://www.esrl.noaa.gov/psd/data/20thC_Rean/) over the same period. This global reanalysis spans the entire twentieth century and assimilates only surface atmospheric pressure, and is therefore independent of the blended wind dataset. We can therefore be more confident in the results presented in this paper. As a side note, the zonal wind trend in 20CR over a much longer period (1960-2011) shows patterns different from those calculated over the last two decades. For example, an intensification of the westerlies in the southern hemisphere is noticeable in high latitudes whereas the zonal trend over 1992-2012 is equivalent to the trend found in the blended wind (Figure 14a). This strong increase in zonal wind speed is expected from the trend present in the Southern Annular Mode index.

The global blended wind product presented in this paper has the potential for broad applications since it offers a quality multiyear forcing function for ocean modelers. It may be used, for example, for large and regional scale studies on interannual (and possibly decadal) variability. In addition, with its effective spatial resolution on the order of $100 \mathrm{~km}$ available 4-times daily, this blended product could also be used to address local and regional air-sea interaction problems. As an example, our group is currently testing the sensitivity of upwelling dynamics to the different forcing frequencies captured by this blended product. The blended product presented in this paper is available on the CERSAT portal (http://www.cersat.ifremer.fr/data) from the publication date with ftp delivery. 


\section{Acknowledgments}

This research was supported by a TOSCA (Terre, Océan, Surfaces Continentales, Atmosphère) project funded by the CNES (Centre National d'Etudes Spatiales). We thank D. Croizé-Fillon, J. F. Piollé, F. Paul, and IFREMER/CERSAT for data processing support. The authors are grateful to ESA, EUMETSAT, CERSAT, JPL, Météo-France, NDBC, PMEL, and UK MetOffice for providing numerical, satellite, and in situ data used in this study. SSM/I and SSMIS data used in this study are produced by Remote Sensing Systems, and, available at Www.remss.com/missions/ssmi. Support for this study has also been provided by Ifremer for AB and FD, by the French Centre National de la Recherche Scientifique (CNRS) for BB, NSF/PO for AMM, NASA/PhO for SAG and IRD (Institut de Recherche pour le Développement) for CR, GC, CM, Université de Bretagne Occidentale for SH. FD is now at the University of Cape Town and is supported by the UMFULA project. 


\section{References}

Beal, R. C., V. N. Kudryavtsev, D. R. Thompson, S. A. Grodsky, D. G. Tilley, V.A. Dulov, and H. C. Graber, 1997: The influence of the marine atmospheric boundary layer on ERS 1 synthetic aperture radar imagery of the Gulf Stream, J. Geophys. Res., 102, 5799-5814

Bentamy, A., P. Queffeulou, Y. Quilfen, K. Katsaros,1999: Ocean surface wind fields estimated from satellite active and passive microwave instruments, IEEE T. Geoscience and Remote Sensing, 37 (5), 2469-2486.

Bentamy A., K B. Katsaros, W. M. Drennan, E. B. Forde, 2002: Daily surface wind fields produced by merged satellite data. American Geophys. Union, Geophysical Monograph Series Vol. $127,343-349$.

Bentamy, A., D. Croize-Fillon, and C. Perigaud, 2008: Characterization of ASCAT measurements based on buoy and QuikSCAT wind vector observations, Ocean Sci., 4, 265-274.

Bentamy, A., K. Katsaros, P. Queffeulou, 2011: Satellite Air - Sea fluxes. In Remote Sensing of the Changing Oceans. Springer Verlag Ed. (Tang, DanLing (Ed.)). http://archimer.ifremer.fr/doc/00030/14101/. 141 - 168.

Bentamy, A. and Croizé-Fillon, D.C., 2012. Gridded surface wind fields from Metop/ASCAT measurements. International journal of remote sensing, 33(6), pp.1729-1754.

Bentamy, A., S. A. Grodsky, J. A. Carton, D. Croizé-Fillon, and B. Chapron, 2012: Matching ASCAT and QuikSCAT winds, J. Geoph. Res., 117, C02011, doi:10.1029/2011JC007479.

Bentamy A., Grodsky S. A., Chapron B., Carton J. A., 2013: Compatibility of C- and Ku-band scatterometer winds: ERS-2 and QuikSCAT. J. Marine System 117-118, 72-80

Bentamy, A., Grodsky, S. A., Elyouncha, A., Chapron, B., \& Desbiolles, F., 2016 : Homogenization of scatterometer wind retrievals. International Journal of Climatology.

Bourassa, M. \& Co-Authors, 2010: Remotely Sensed Winds and Wind Stresses for Marine Forecasting and Ocean Modeling in Proceedings of OceanObs'09: Sustained Ocean 
Observations and Information for Society (Vol. 2), Venice, Italy, 21-25 September 2009, Hall, J., Harrison, D.E. \& Stammer, D., Eds., ESA Publication WPP-306, doi:10.5270/OceanObs09.cwp.08.

Carton, J.A., and Giese, B.S., 2008: A reanalysis of ocean climate using simple ocean data assimilation (SODA). Monthly Weather Review, 136, 2999-3017.

Chelton, D.B., M.G. Schlax, M.H. Freilich, and R.F. Milliff (2004), Satellite measurements reveal persistent small-scale features in ocean winds. Science, 303, 978-983.

Chelton, D. B., Freilich, M. H., Sienkiewicz, J. M., \& Von Ahn, J. M. (2006). On the use of QuikSCAT scatterometer measurements of surface winds for marine weather prediction. Monthly Weather Review, 134(8), 2055-2071.

Colberg, F., \& Reason, C. J. C. (2007). Ocean model diagnosis of low-frequency climate variability in the South Atlantic region. Journal of Climate, 20(6), 1016-1034.

Dee, D.P., Uppala, S.M., Simmons, A.J., Berrisford, P., Poli, P., Kobayashi, S., Andrae, U., Balmaseda, M.A., Balsamo, G., Bauer, P. and Bechtold, P., 2011. The ERA $\square$ Interim reanalysis: Configuration and performance of the data assimilation system. Quarterly Journal of the Royal Meteorological Society, 137(656), pp.553-597.

Debernard, J., Sætra, Ø. and Røed, L.P., 2002. Future wind, wave and storm surge climate in the northern North Atlantic. Climate research, 23(1), pp.39-49.

Desbiolles, F., Blanke, B. and Bentamy, A., 2014a. Short $\square$ term upwelling events at the western African coast related to synoptic atmospheric structures as derived from satellite observations. Journal of Geophysical Research: Oceans, 119(1), pp.461-483.

Desbiolles, F., Blanke, B., Bentamy, A. and Grima, N., 2014b. Origin of fine $\square$ scale wind stress curl structures in the Benguela and Canary upwelling systems. Journal of Geophysical Research: Oceans, 119(11), pp.7931-7948. 
Desbiolles, F., Blanke, B., Bentamy, A., \& Roy, C., 2016. Response of the Southern Benguela upwelling system to fine-scale modifications of the coastal wind. Journal of Marine Systems, $156,46-55$.

Ebuchi, N., H. C. Graber, and M. J. Caruso, 2002: Evaluation of wind vectors observed by QuikSCAT/SeaWinds using ocean buoy data. J. Atmos. Oceanic Technol., 19, 2049-2069.

Fairall, C. W., Bradley, E. F., Hare, J. E., Grachev, A. A., \& Edson, J. B., 2003. Bulk parameterization of air-sea fluxes: Updates and verification for the COARE algorithm. Journal of Climate, 16(4), 571-591.

Fore, A. G., Stiles, B. W., Chau, A. H., Williams, B., Dunbar, R. S., \& Rodriguez, E. (2014). Pointwise wind retrieval and ambiguity removal improvements for the QuikSCAT climatological data set. Geoscience and Remote Sensing, IEEE Transactions on, 52(1), 51-59.

Freilich M. H and R. S. Dunbar, 1999: The accuracy of the NSCAT 1 vector winds: Comparisons with National Data Buoy Center buoys. Jour. Geophys. Res. Vol. 104, No C5, 11,231 $11,246$.

Graber H. C., N. Ebutchi, R. Vakkayil, 1996: Evaluation of ERS-1 scatterometer winds with wind and wave ocean buoy observations, Tech. Report, RSMAS 96-003, Division of Applied Marine Physics, RSMAS, Univ. of Miami, Florida 33149-1098, USA, 58 pp.

Grima, N., A. Bentamy, K. Katsaros, and Y. Quilfen, 1999: Sensitivity of an oceanic general circulation model forced by satellite wind stress fields, J. Geophys. Res., 104, 7967-7989, doi:10.1029/1999JC900007.

Grodsky, S.A., Kudryavtsev, V.N., Bentamy, A., Carton, J.A. and Chapron, B., 2012. Does direct impact of SST on short wind waves matter for scatterometry?. Geophysical Research Letters, $39(12)$.

Hasselmann, S., Hasselmann, K., Bauer, E., Janssen, P.A.E.M., Komen, G.J., Bertotti, L., Lionello, 
P., Guillaume, A., Cardone, V.C., Greenwood, J.A., Reistad, M., Zambresky, L. and Ewing, J.A. (1988). The WAM model a third generation ocean wave prediction model. Journal of Physical Oceanography 18, 1775- 1810.

Held, I. M., \& Soden, B. J. (2006). Robust responses of the hydrological cycle to global warming. Journal of Climate, 19(21), 5686-5699.

Hersbach H., 2010: Comparison of C-Band Scatterometer CMOD5.N Equivalent Neutral Winds with ECMWF. J. Atmos. Oceanic Technol., 27, 721-736. doi: http://dx.doi.org/10.1175/2009JTECHO698.1

Lee, T., Wang, O., Tang, W. and Liu, W.T., 2008. Wind stress measurements from the QuikSCAT $\square$ SeaWinds scatterometer tandem mission and the impact on an ocean model. Journal of Geophysical Research: Oceans, 113(C12).

Lefèvre, J., Marchesiello, P., Jourdain, N. C., Menkes, C., \& Leroy, A. (2010). Weather regimes and orographic circulation around New Caledonia. Marine pollution bulletin, 61(7), 413-431.

Mestas-Nuñez, A. M., Kelly, F. J., Bentamy, A., \& Katsaros, K. B. (2013). The ENSO footprint in monthly satellite evaporation over the global ocean during 1993-2007. Remote Sensing Letters, 4(7), 706-714.

Milliff, R. F., Morzel, J., Chelton, D. B., \& Freilich, M. H. (2004). Wind stress curl and wind stress divergence biases from rain effects on QSCAT surface wind retrievals. Journal of atmospheric and oceanic technology, 21(8), 1216-1231.

O’Neill, Larry W., Dudley B. Chelton, Steven K. Esbensen, and Frank J. Wentz, 2005. Highresolution satellite measurements of the atmospheric boundary layer response to SST variations along the Agulhas Return Current. Surface Wind Modification Near Mid-Latitude Ocean Fronts: Observational and Dynamical Analysis (2005): 54.

Portabella, M. and A.C.M. Stoffelen 2009: On Scatterometer Ocean Stress, J. Atm. Oceanic 
Technol., 26, 2, 368-382, doi:10.1175/2008JTECHO578.1.

Quilfen, Y., 1995: ERS-1 off-line wind scatterometer products. IFREMER Tech. Rep., 75 pp.

Reason, C. J. C., Allan, R. J., Lindesay, J. A., \& Ansell, T. J. (2000). ENSO and climatic signals across the Indian Ocean basin in the global context: Part I, Interannual composite patterns. International Journal of Climatology, 20(11), 1285-1327.

Reynolds, R.W., T.M. Smith, C. Liu, D.B. Chelton, K.S. Casey, and M.G. Schlax (2007), Daily high-resolution-blended analyses for sea surface temperature. J. Climate, 20, 5473-5496.

Ricciardulli L. and F.J. Wentz, 2013: Integrating multiple scatterometer observations into a climate data record of ocean vector winds, presented at IOVWST 2013, Kona, Hawaii.

Risien, C. M., \& Chelton, D. B. (2008). A global climatology of surface wind and wind stress fields from eight years of QuikSCAT scatterometer data. Journal of Physical Oceanography, 38(11), 2379-2413.

Saha, S., and co-authors (2010). The NCEP Climate Forecast System reanalysis. Bulletin of the American Meteorological Society, 1015-1057, doi: 10.1175/2010BAMS3001.1.

Schlüssel, P., Schanz, L., \& Englisch, G. (1995). Retrieval of latent heat flux and longwave irradiance at the sea surface from SSM/I and AVHRR measurements. Advances in Space Research, 16(10), 107-116.

Schott, F.A. and McCreary, J.P., 2001. The monsoon circulation of the Indian Ocean. Progress in Oceanography, 51(1), pp.1-123.

Simmons A, Uppala S, Dee D, Kobayashi S. 2006: ERA-Interim: New ECMWF reanalysis products from 1989 onwards. ECMWF Newsletter 110: 26 - 35 .

Small, R. J., Xie, S. P., O’Neill, L., Seo, H., Song, Q., Cornillon, P., Spall, M., and Minobe, S. (2008). Air-sea interaction over ocean fronts and eddies. Dynamics of Atmospheres and Oceans, 45(3), 274-319. 
Stiles, B. (2014), “Discovering a decade of coastal winds from scatterometers", IOVWST (International Ocean Vector Winds Science Team) meeting sponsored by NASA, FSU, COAP, EUMETSAT, CNES, ESA and Ifremer, Brest, France, 2-4 June.

Sudha A. K. And C.V.K Prasada Rao, 2013: Comparison of Oceansat-2 scatterometer winds with buoy observations over the Indian Ocean and the Pacific Ocean. Remote sensing Letters. Vol.4, Issue 2, doi:10.1080/2150704X.2012.713140. 171-179 pp.

Tokinaga, H., \& Xie, S. P. (2011). Wave-and Anemometer-Based Sea Surface Wind (WASWind) for Climate Change Analysis. Journal of Climate, 24(1), 267-285.

Tolman, H.L. (2002). User manual and system documentation of WAVEWATCH III version 2.22. Technical Report 222, NOAA/NWS/NCEP/MMAB.

Verspeek, J.; A. Stoffelen, M, Portabella, H. Bonekamp, C. Anderson, and J.F. Saldana, 2010: Validation and Calibration of ASCAT Using CMOD5.n, IEEE Transactions on Geoscience and Remote Sensing, 48, 386-395, doi: 10.1109/TGRS.2009.2027896.

Wentz, F. J. (1997). A well calibrated ocean algorithm for special sensor microwave/imager. Journal of Geophysical Research: Oceans (1978-2012), 102(C4), 8703-8718.

Wentz, F. J. and D. K. Smith, 1999: A model function for the ocean-normalized radar cross section at $14 \mathrm{GHz}$ derived from NSCAT observations. J. Geophys. Res., 104, 11 499-11 514.

Wentz, F. J., Ricciardulli, L., Hilburn, K., \& Mears, C. (2007). How much more rain will global warming bring?. Science, 317(5835), 233-235.

Wentz, F.J., K.A. Hilburn, D.K. Smith, 2012: Remote Sensing Systems SSM/I and SSMIS, Daily Global Environmental Suite on $0.25 \mathrm{deg}$ grid, Version 7. Remote Sensing Systems, Santa Rosa, CA. Available online at www.remss.com/missions/ssmi.

Wunsch, C., P. Heimbach, R.M. Ponte, I. Fukumori, and the ECCO-GODAE Consortium Members. 2009. The global general circulation of the ocean estimated by the ECCO-Consortium. 
Oceanography 22(2):88-103, doi:10.5670/oceanog.2009.41

Xie, S. P., \& Philander, S. G. H. (1994). A coupled ocean $\square$ atmosphere model of relevance to the ITCZ in the eastern Pacific. Tellus A, 46(4), 340-350.

Xie, S. P., Deser, C., Vecchi, G. A., Ma, J., Teng, H., \& Wittenberg, A. T. (2010). Global warming pattern formation: sea surface temperature and rainfall. Journal of Climate, 23(4), 966-986.

Young, I. R., Zieger, S., \& Babanin, A. V. (2011). Global trends in wind speed and wave height. Science, 332(6028), 451-455.

Yu, J. Y., Kao, H. Y., \& Lee, T. (2010). Subtropics-related interannual sea surface temperature variability in the central equatorial Pacific. Journal of Climate, 23(11), 2869-2884. 


\section{Table and Figure captions:}

Table 1: Main characteristics of various satellite scatterometer wind products.

Table 2: Statistical comparison results of collocated 6-hourly offshore NDBC, blended, and ERAInterim 10m wind speed and direction. They are shown for the whole study period (1992 - 2012) and for ERS-1 (March 1992 - June 1996), ERS-2 (March 1996 - January 2001), QuikSCAT (July 1999 - November 2009), and ASCAT (March 2007 - March 2012) operating periods. Bias is defined as the mean difference between buoy and blended winds (in this order). Std, bs, $r^{2}$, and $\rho^{2}$ indicate the standard deviation, regression symmetrical coefficient, scalar correlation coefficient, and vector correlation coefficient, respectively. The latter varies between -2 and +2 . Statistics that rely on comparisons between NDBC and ERA-Interim are shown within brackets.

Table 3: Same as Table 2 but for nearshore NDBC wind data.

Table 4: Same as Table 2 but for tropical buoy data (TAO, PIRATA, RAMA). Statistics that rely on comparisons between buoy data and ERA-Interim are shown within brackets.

Figure 1: Sampling of remotely sensed data as a function of latitude. Results are shown for all data (including scatterometer, left column) and for only scatterometer retrievals (right column) in January 1994 ( st $^{\text {sow }), ~ J a n u a r y ~} 1998$ ( $2^{\text {nd }}$ row $)$, January 2002 ( $3^{\text {rd }}$ row $)$, and January 2010 ( $4^{\text {th }}$ row $)$. Colors indicate the data numbers for the 00:00, 06:00, 12:00, and 18:00 analyses.

Figure 2: Spatial distributions of the mean (bias, left column) and standard deviation (STD, central 
column) difference and correlation coefficient (right column) characterizing original and simulated wind speed fields. They are estimated from 6-hourly datasets calculated for January 1994 (first row), January 1998 (second row), January 2002 (third row), and January 2010 (last row).

Figure 3: Root Mean Square Error (RMSE) for December 1999 between the blended product incorporating all the data (top row), the blended product processed without QSCAT data (middle row) and ERA-Interim reanalyses (bottom row), and QSCAT L2 data considered here as a reference. Wind speed, and $\mathrm{u}$ and $\mathrm{v}$ components are analyzed separately and presented in the $1 \mathrm{st}$, 2nd, and last column, respectively.

Figure 4: Time series of the statistical parameters characterizing the comparison between offshore NDBC and blended 6-hourly wind speed (red), zonal (blue), and meridional (black) components: a) mean difference (Bias), b) Standard deviation (STD) difference, c) scalar correlation coefficient $(\rho)$, and d) sampling length.

Figure 5: (a) Blended wind analysis for 15 December 1999 (wind speed in color and wind direction as arrows); the 4 epochs of the day have been averaged. (b) ERA-Interim wind speed (color) and direction (arrows); the 4 epochs of the day have been averaged. (c) QuikSCAT wind speed and direction for 15 December 1999. For clarity, only the wind speeds larger than $10 \mathrm{~m} / \mathrm{s}$ are drawn as vectors in all cases.

Figure 6: (a,b,c) Curl of the wind field presented in Figures 5a (Blended), 5b (ERA-Interim), and 5c (QuikSCAT), respectively. (d,e,f) Divergence of the wind field presented in Figures 5a (Blended), 5b (ERA-Interim), and 5c (QuikSCAT), respectively. 
Figure 7: (a) Wind speed perturbations (in color) and SST perturbations (contours) for 15

December 1999 over the Agulhas and Benguela upwelling system regions. Perturbation fields are referred as the spatially high-pass filtered fields. These fields are obtained by first isolating largescale features of both wind speed and SST by applying a Lanczos filter with half-power filter cutoff wavelengths of $10^{\circ}$ in both latitude and longitude. See text for more details. (b) Binned scatter plot over 1999 of the 15-day running averages of the SST and wind speed perturbations over the Agulhas regions.

Figure 8: Wave number spectra of the blended (bold line), ERA-Interim (dotted line) and QuikSCAT (thick line) products for the wind speed (a), and the zonal (b) and meridional (c) wind components. The theoretical profiles in $\mathrm{k}^{-2}$ and $\mathrm{k}^{-4}$ are drawn for the comparison.

Figure 9: Mean biases (color) and standard deviation biases (contours) between ERA-Interim and the blended description of the day-night mean differences during the year 1999.

Figure 10: Boreal winter (a) and summer (b) seasonal average of the blended wind speed calculated over the 20-year period of the analysis (DJF: December-January-February; JJA: JuneJuly-August). The contour lines represent the standard deviation of the wind speed (contours are plotted every $0.2 \mathrm{~m} / \mathrm{s}$ from $1 \mathrm{~m} / \mathrm{s}$ ) and arrows show the mean direction of the wind. Only vectors for which the average intensity is higher than $7 \mathrm{~m} / \mathrm{s}$ are drawn in both cases.

Figure 11: Same as Figure 10 but for the wind curl and divergence. 
Figure 12: Power spectra of the monthly-averaged zonal (dashed lines) and meridional wind components (thick lines with stars) as well as wind speed (bold lines), spatially averaged over the northern Pacific (a) and Atlantic ocean (b), over the eastern equatorial Pacific (c) and over the Indian Ocean (d). Both northern Atlantic and Pacific are defined north of $50^{\circ} \mathrm{N}$; the equatorial Pacific and Indian area are bounded as $\left[5^{\circ} \mathrm{S}-5^{\circ} \mathrm{N}, 90-150^{\circ} \mathrm{W}\right]$ and $\left[30^{\circ} \mathrm{S}-20^{\circ} \mathrm{N}, 40^{\circ} \mathrm{E}-100^{\circ} \mathrm{E}\right]$, respectively.

Figure 13: Scalar wind trends for the blended winds (a) and for ERA-Interim (b). Trend values with significance lower than $80 \%$ are plotted with shaded colors.

Figure 14: Trends of the zonal (a) and meridional (b) wind components of the blended product. Trend values with significance lower than $80 \%$ are plotted with shaded colors.

Figure 15: (a) Zonally averaged significant wind speed trends for the blended winds (black line) and ERA-Interim (grey line). (b) Zonally averaged trends of the blended wind speed (solid line), as well as the blended zonal and meridional components (dashed and dotted lines respectively) as a function of latitude, for the 4 oceans (Pacific, Atlantic, Indian and Southern Ocean). In both cases, thin lines show the zonally averaged significant trends while bold lines represent the same signal running-averaged over a window of $7^{\circ}$ in latitudes. 

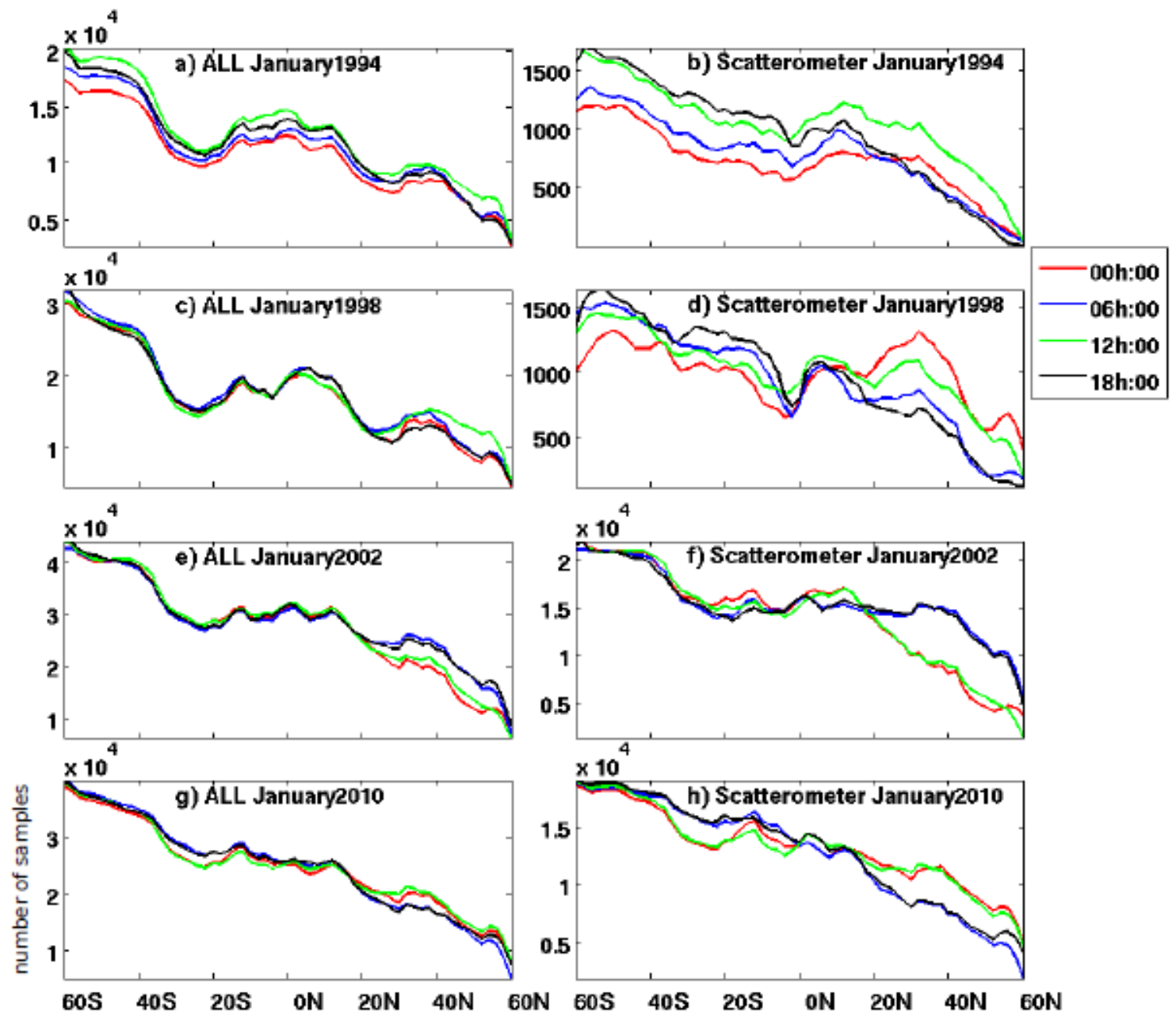

Figure 1 

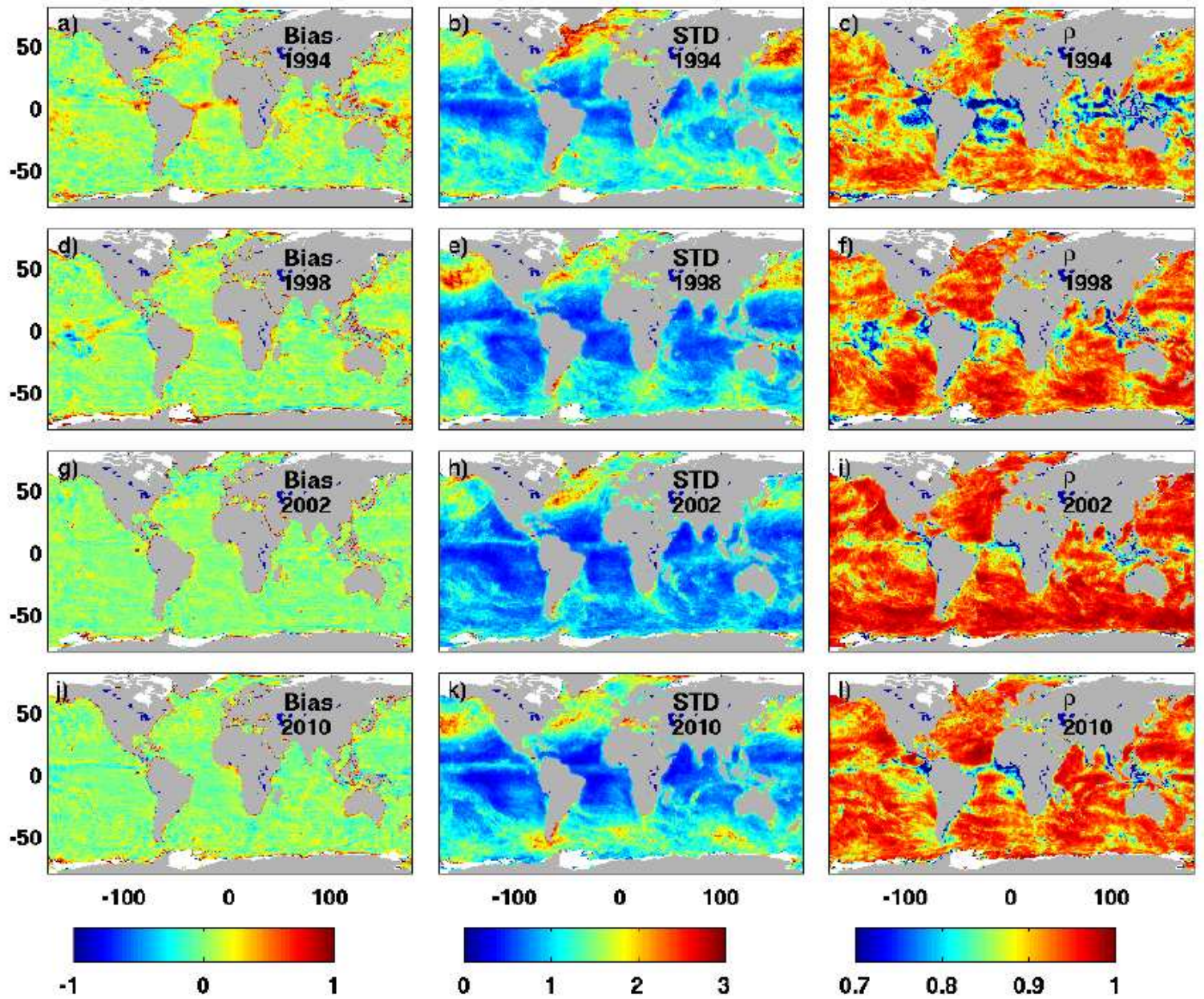

Figure 2 

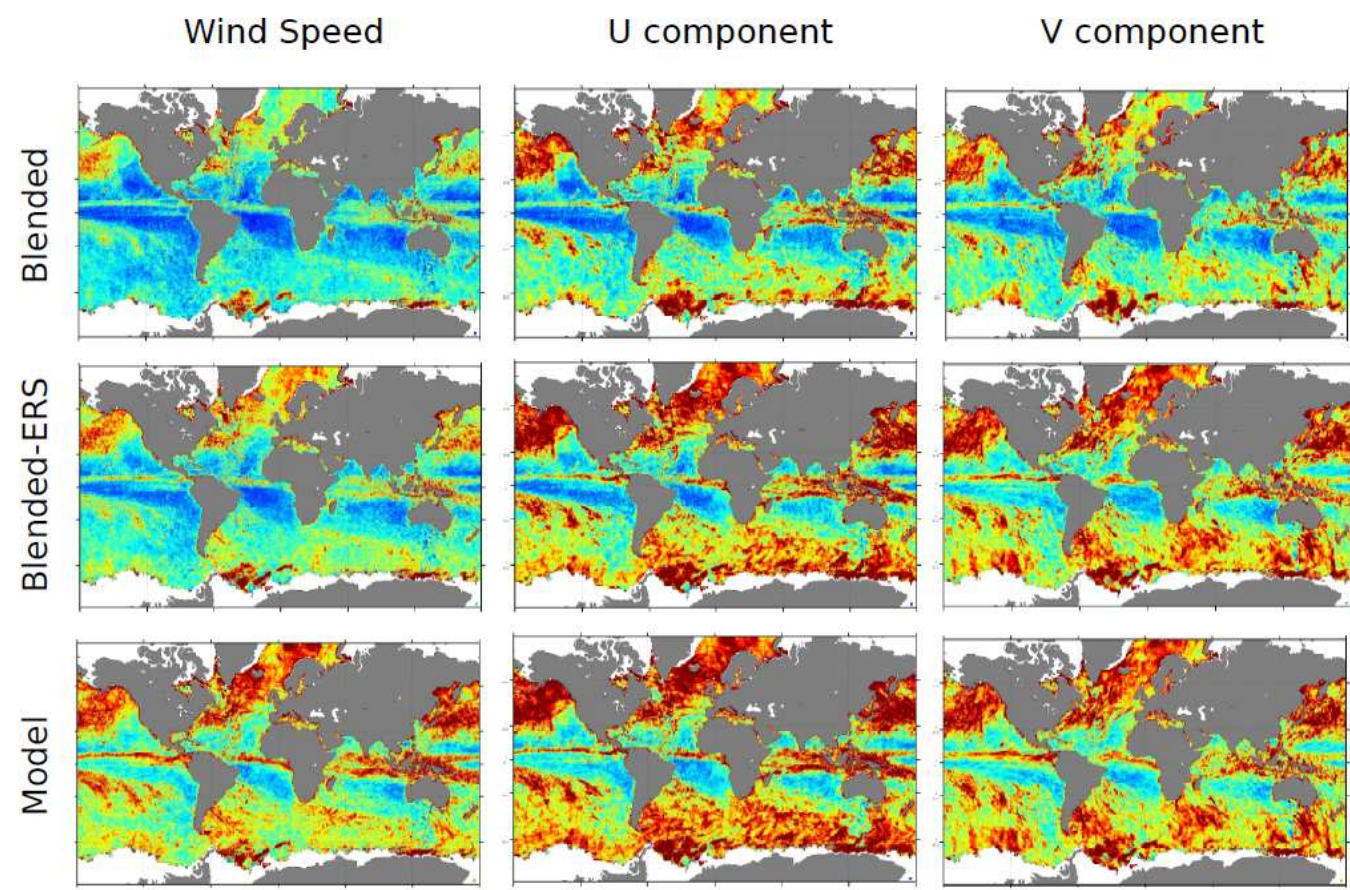

Figure 3 

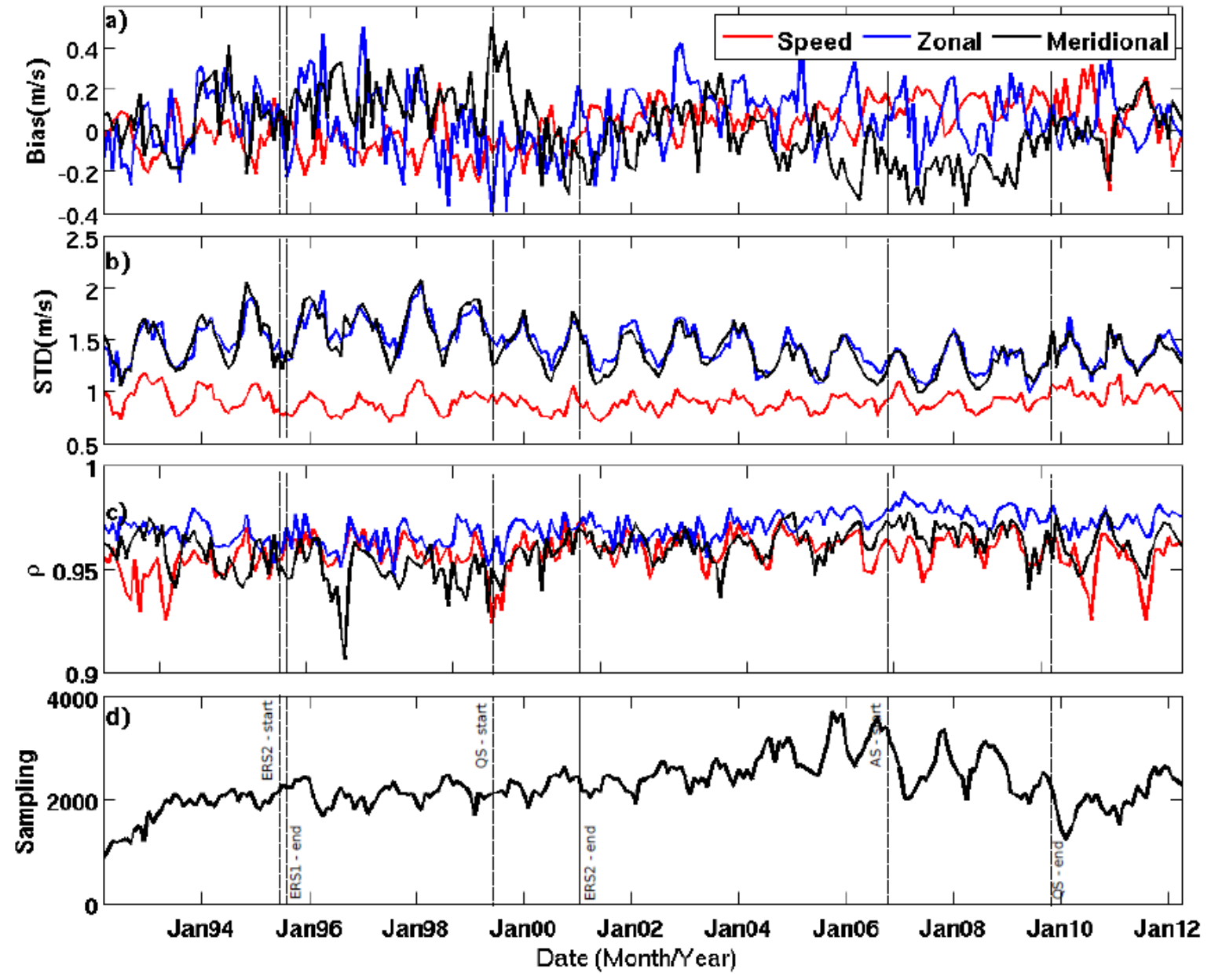

Figure 4 
(a)

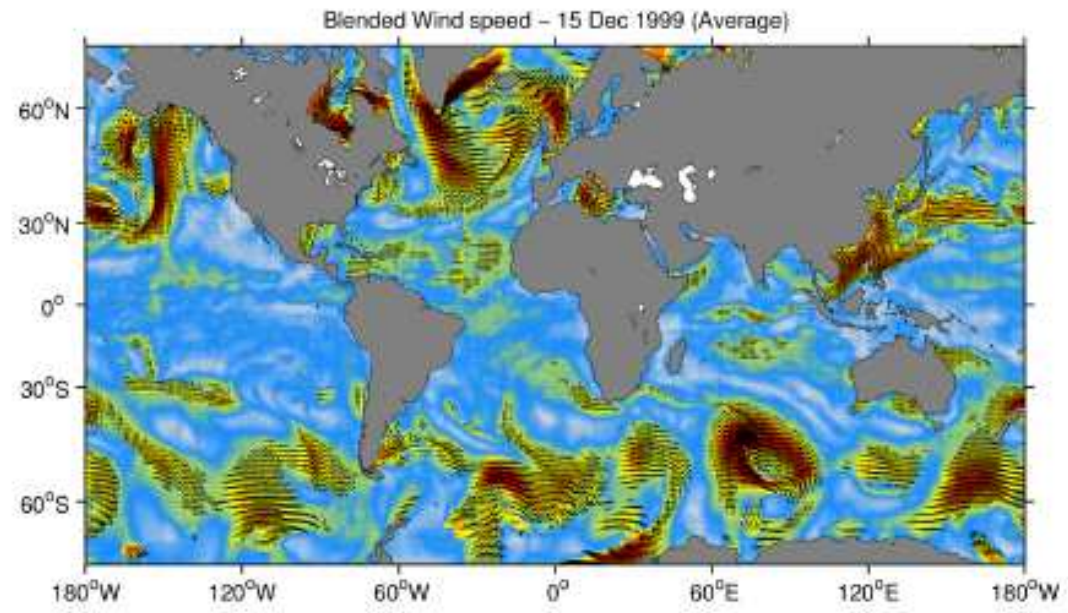

(b)

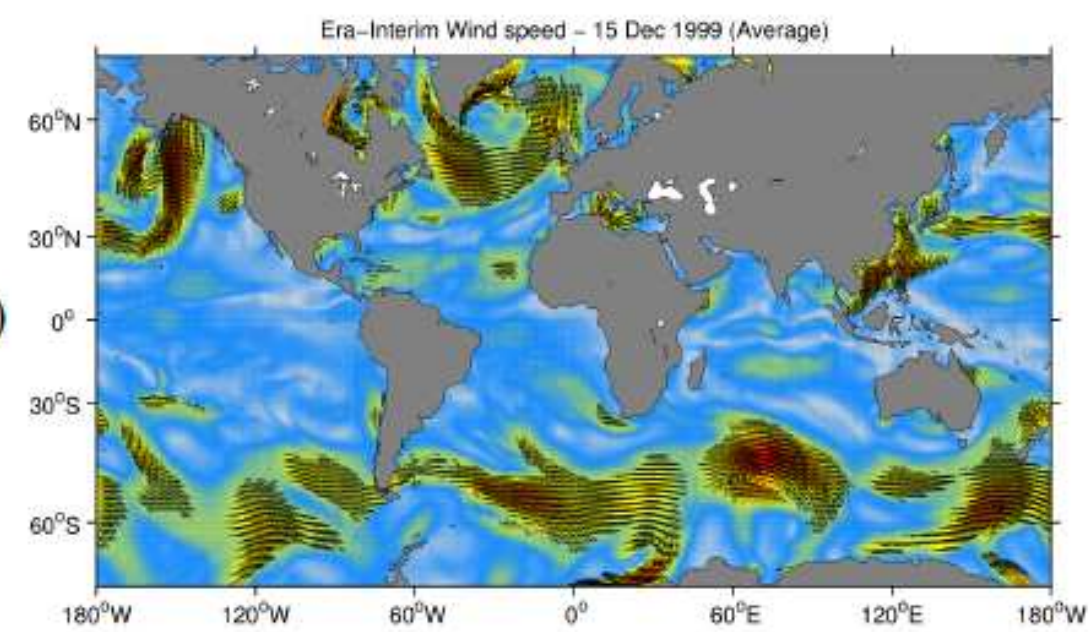

(c)

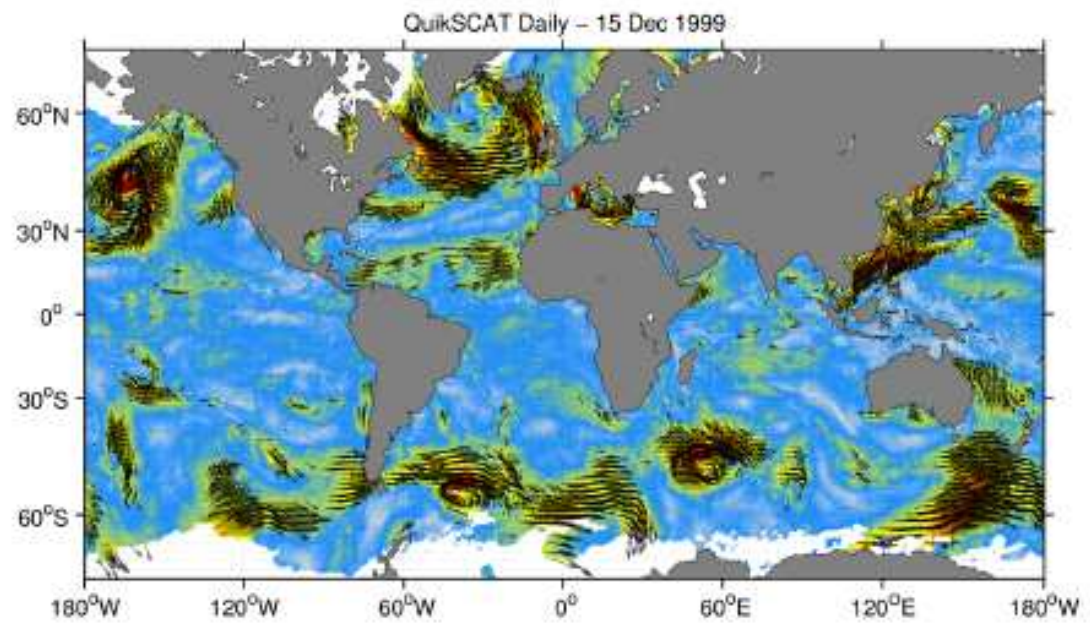

Figure 5 
(a)

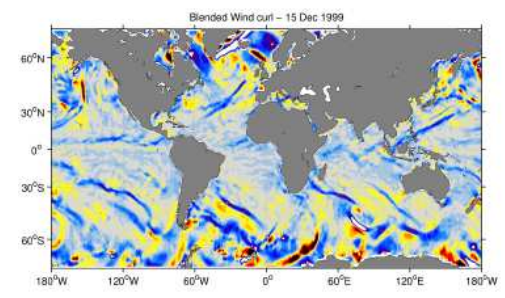

(d)
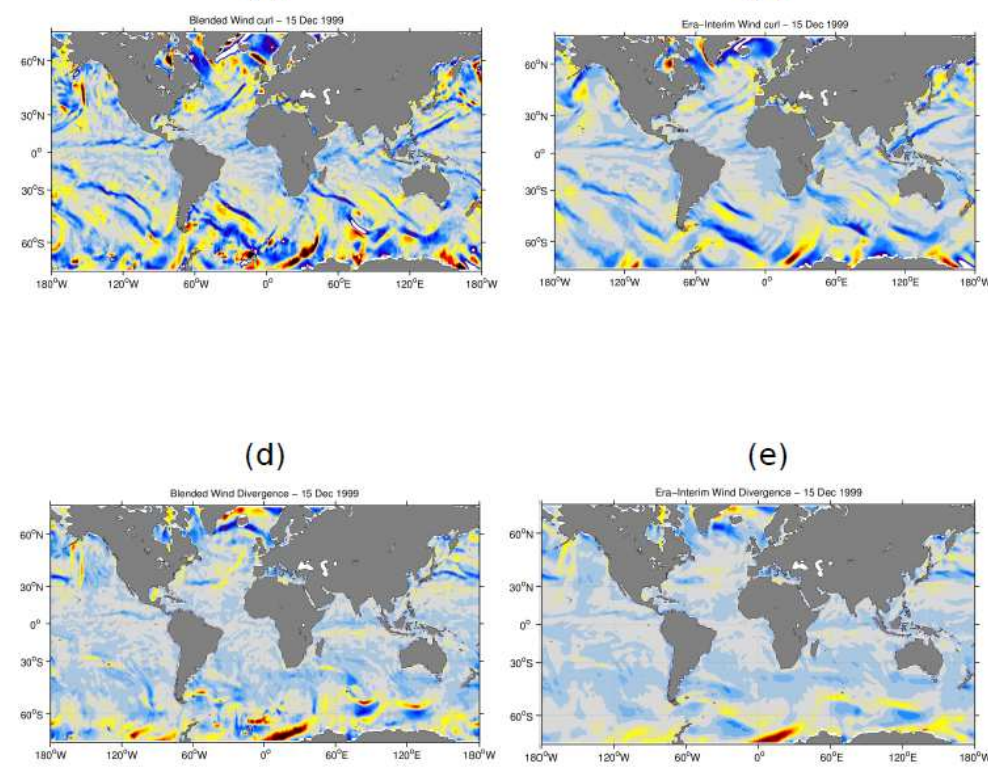

(e) (c)

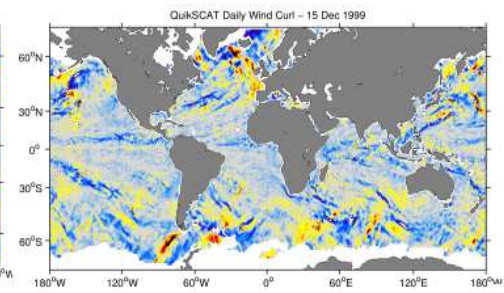

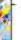
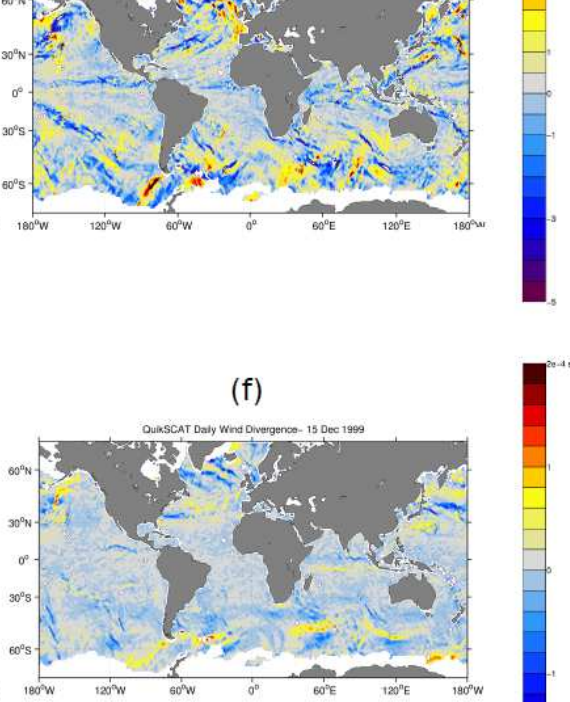

Figure 6 

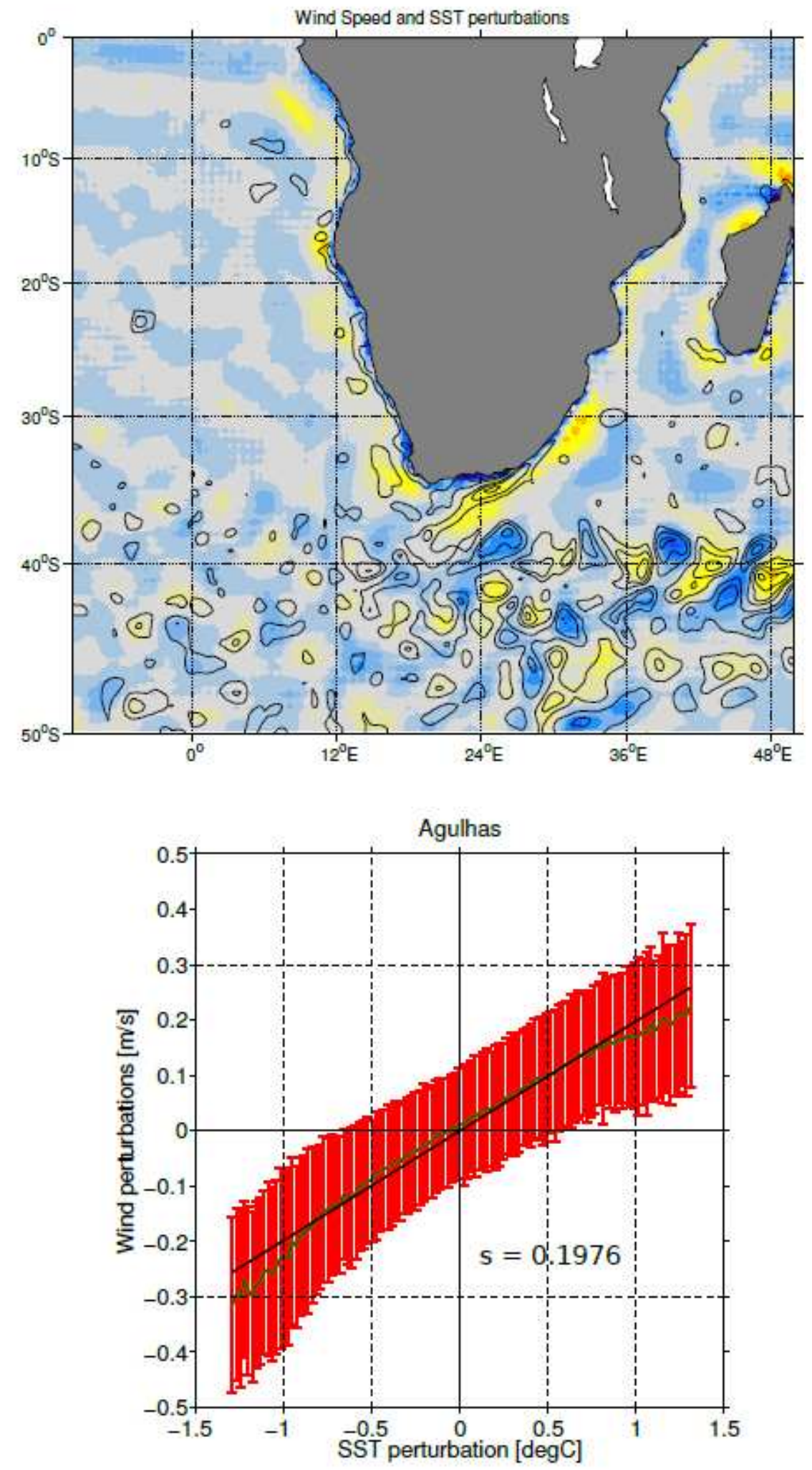

Figure 7 


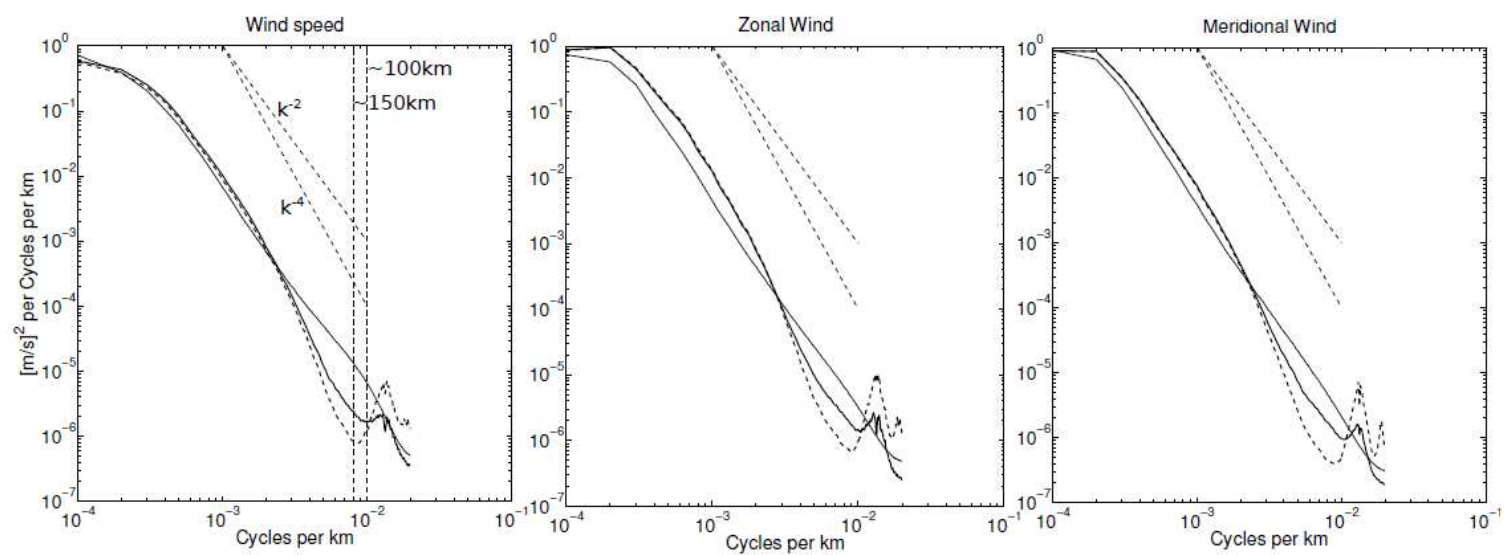

Figure 8 

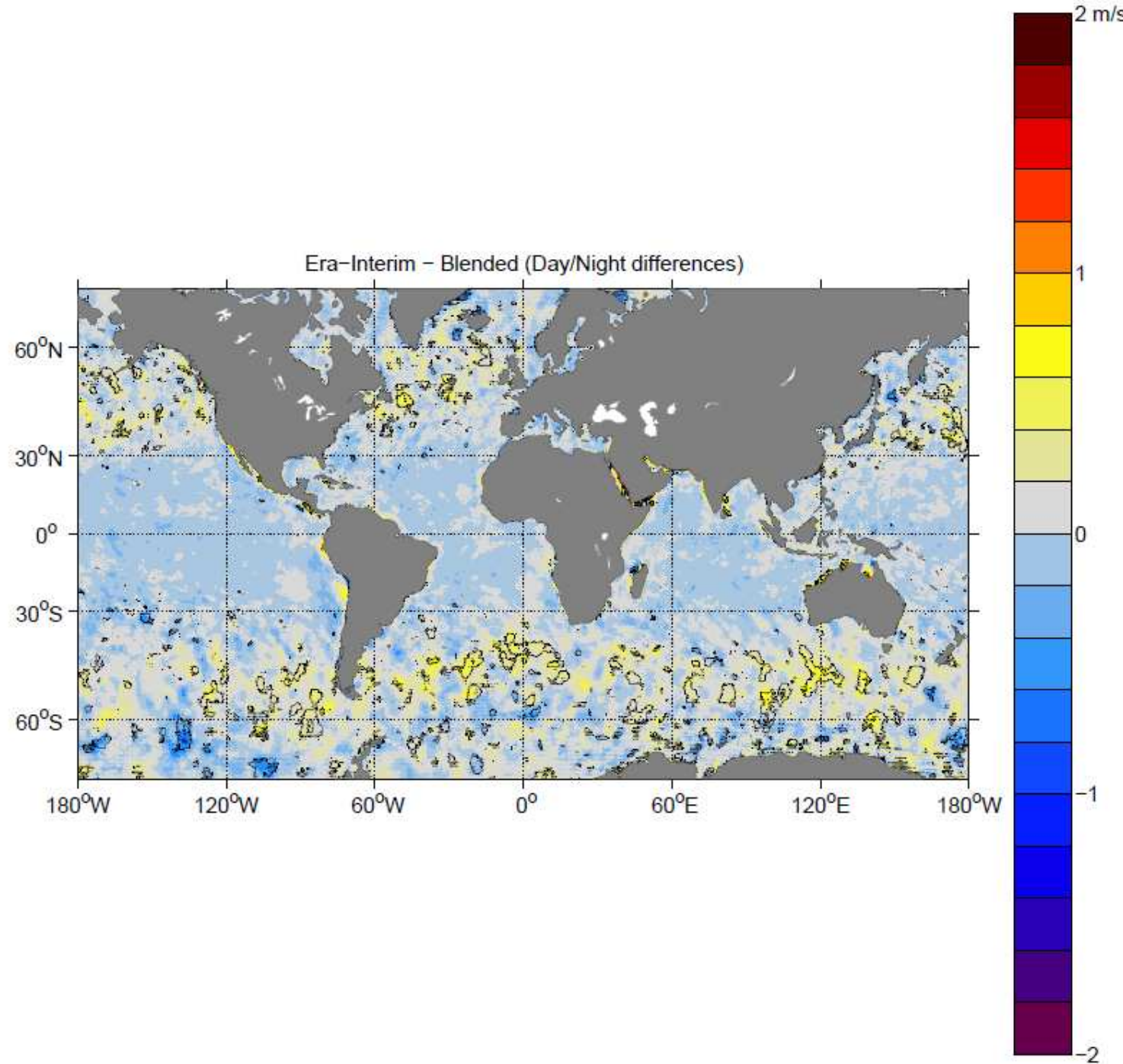

Figure 9 
(a)

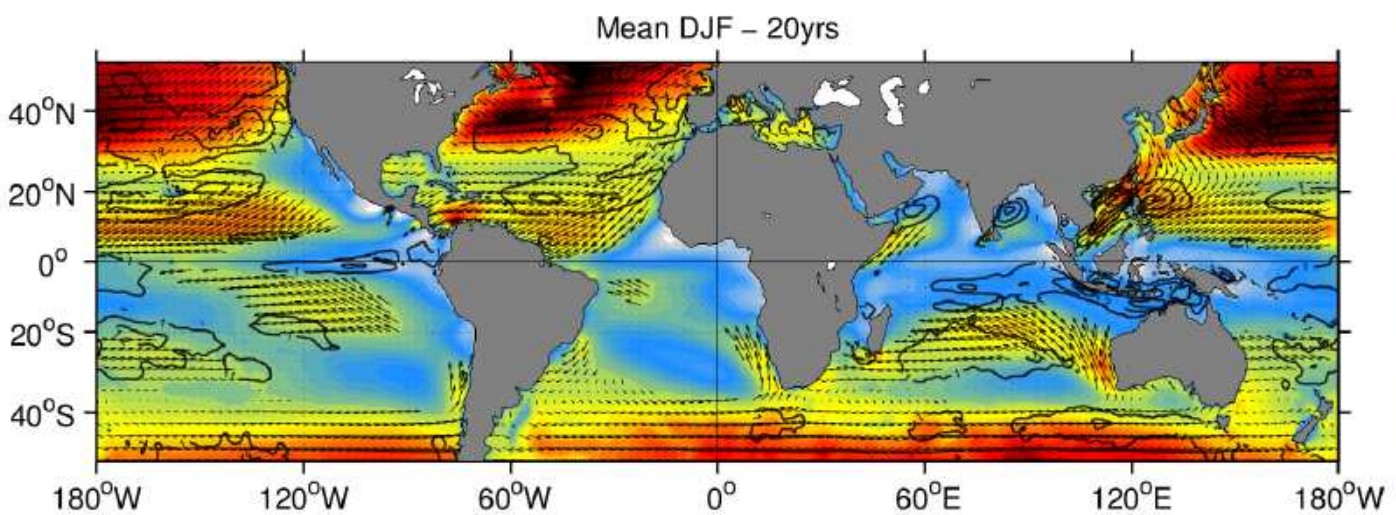

(b)
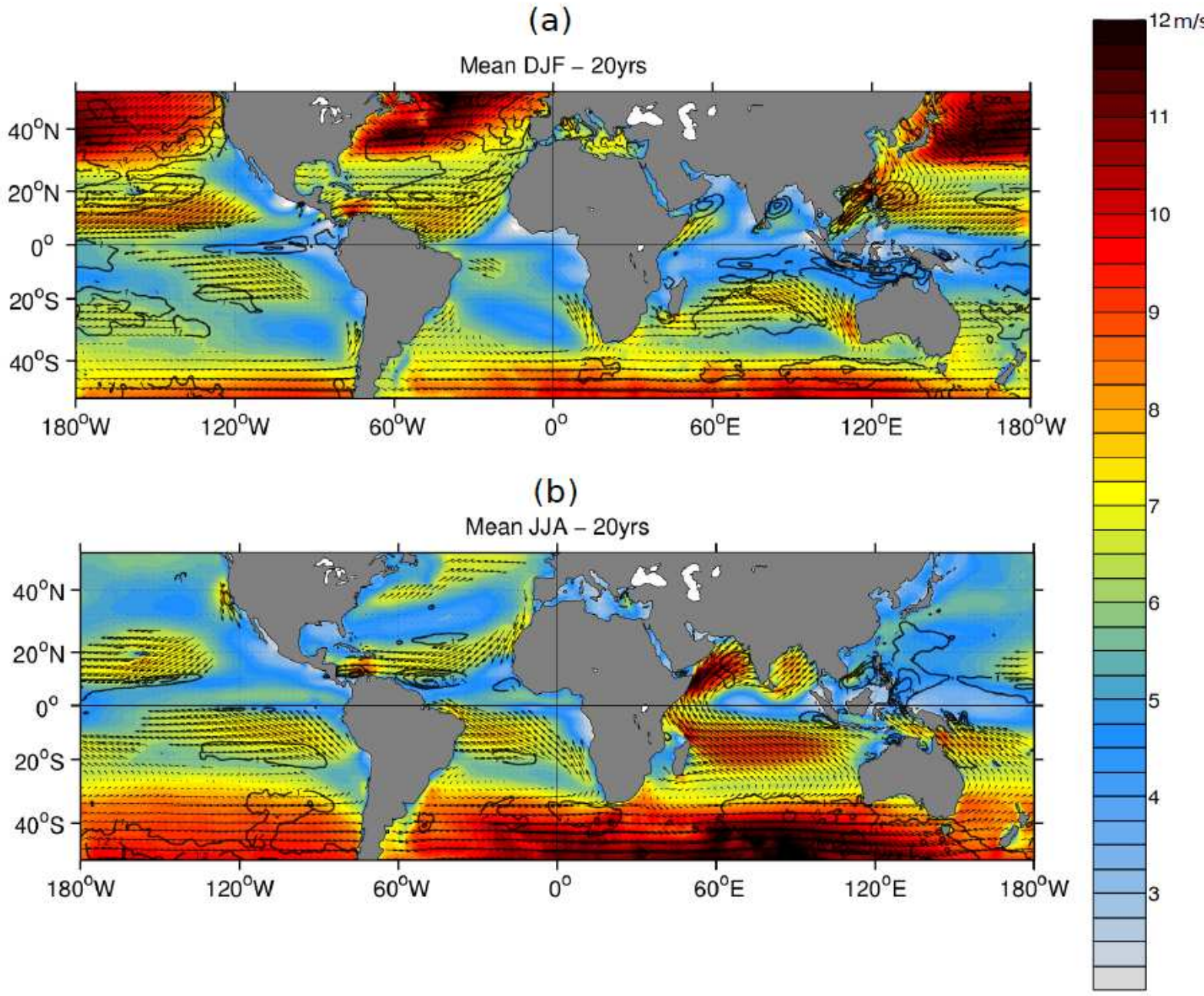

Figure 10 
(a)

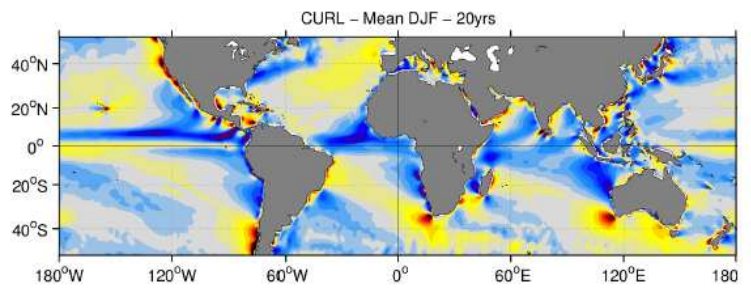

(c)

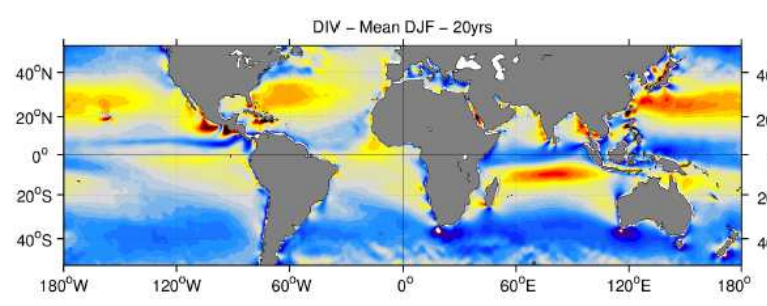

(b)

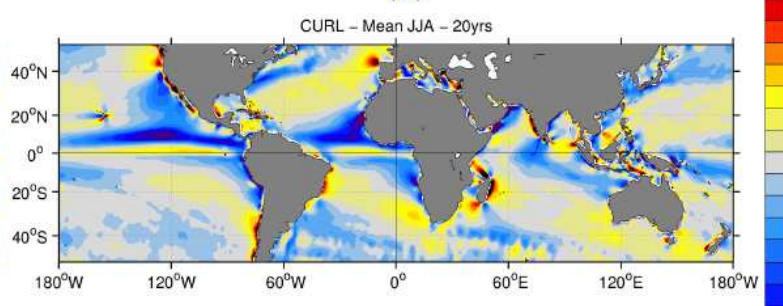

(d)

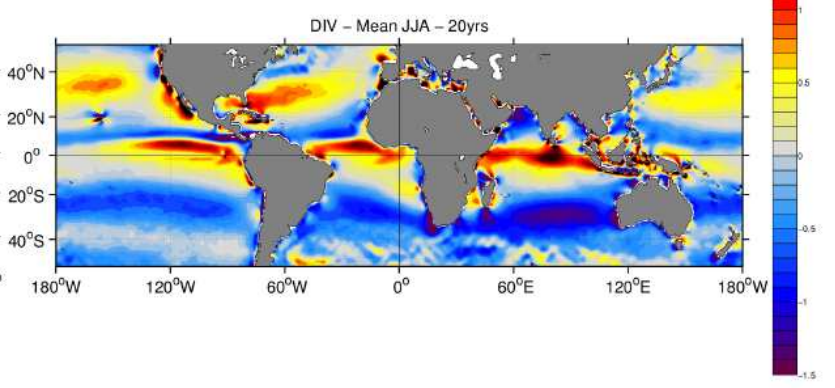

Figure 11 
(a)

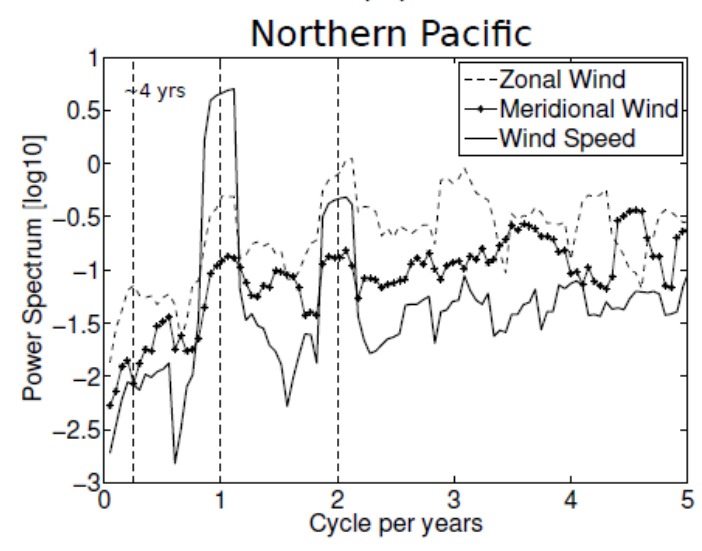

(c)

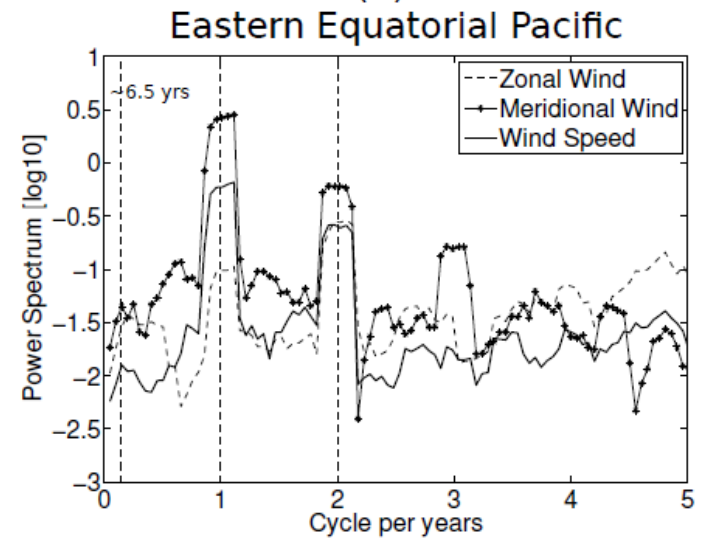

(b)

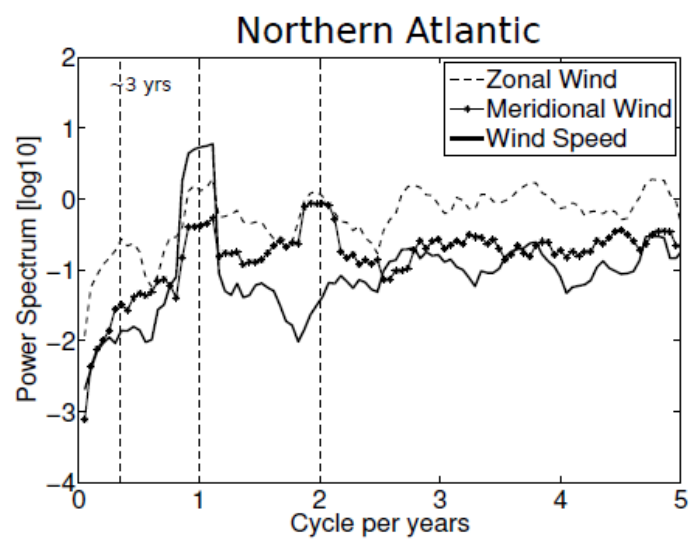

(d)

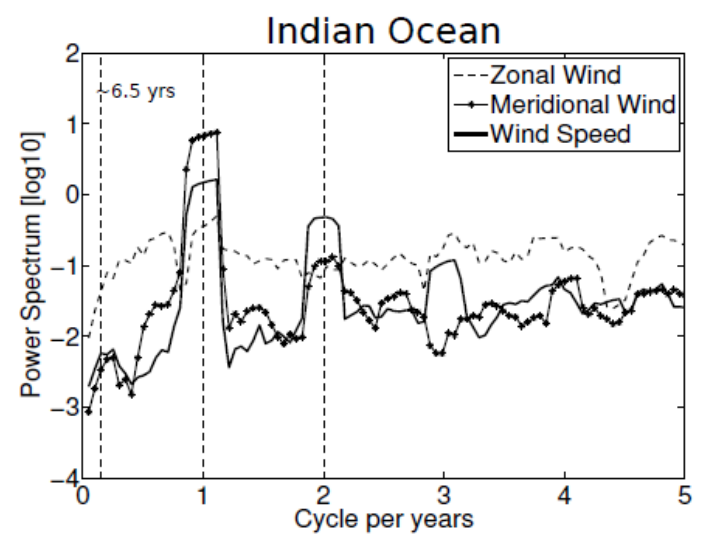

Figure 12 
(a)
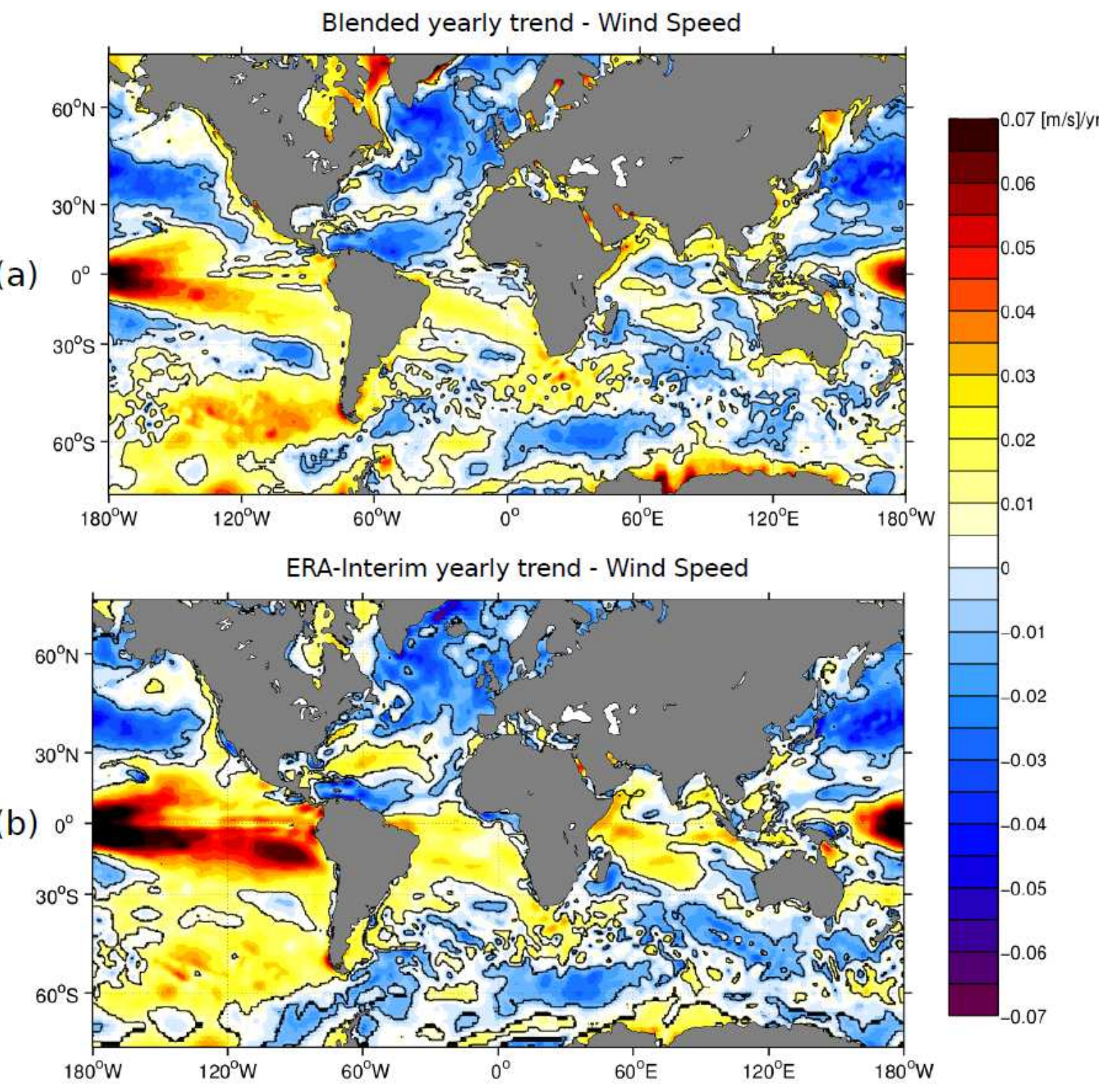

Figure 13 


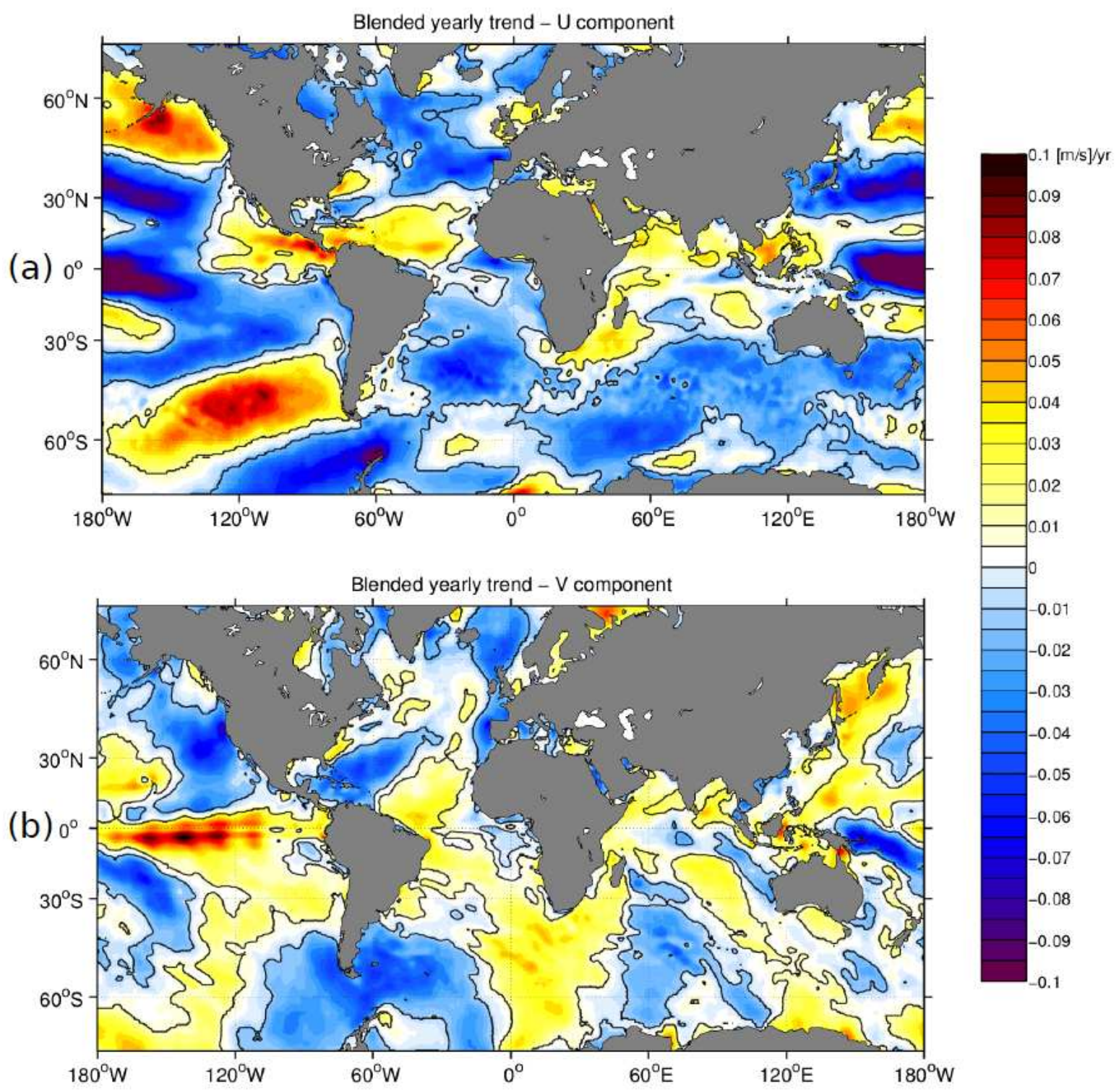

Figure 14 


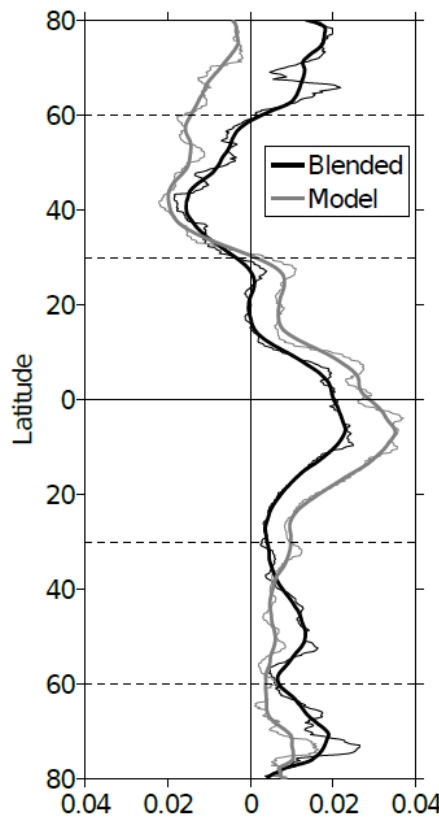

Wind Speed Trend per Year [m/s]/yr

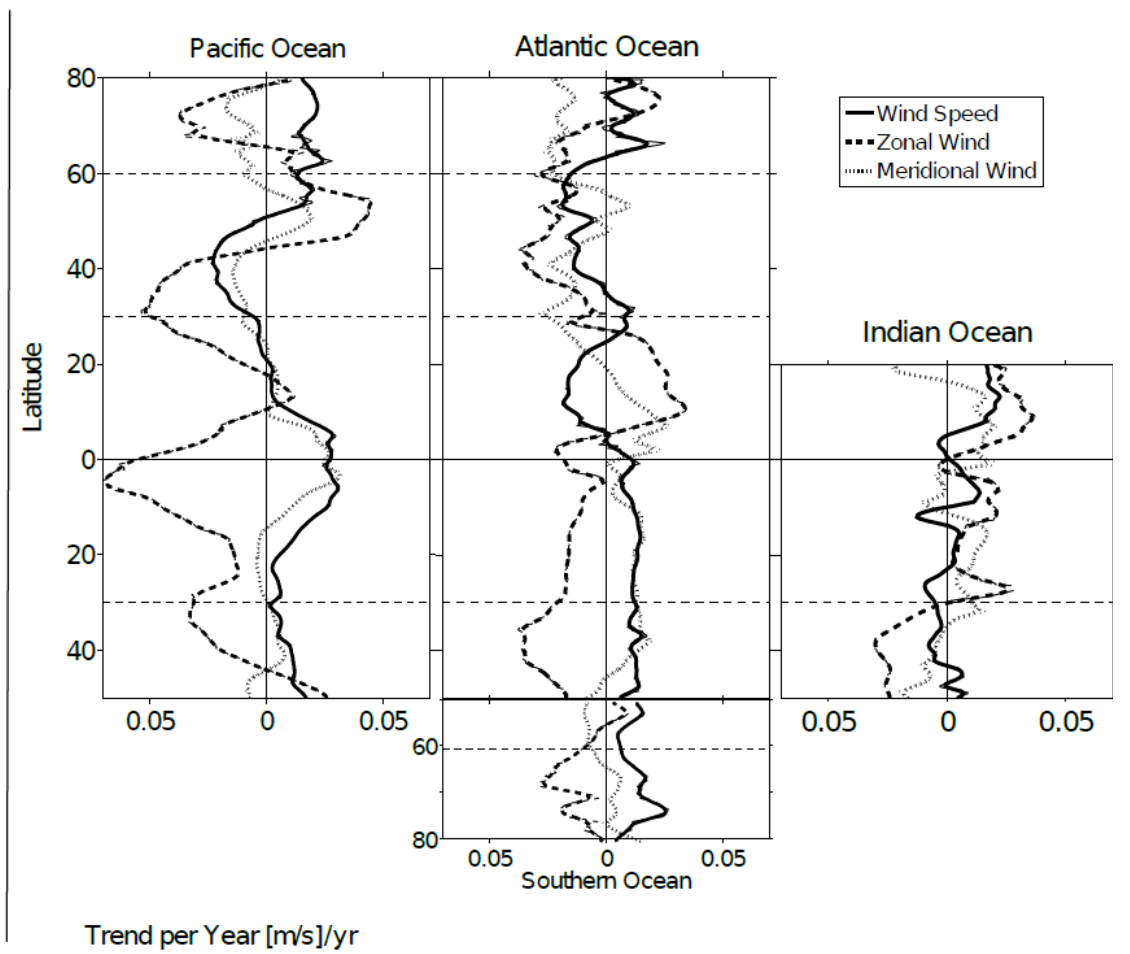

(b)

Figure 15

(a) 
Table 1: Summary of scatterometer's mission characteristics and L2 wind product characteristics.

\begin{tabular}{|c|c|c|c|c|}
\hline Scatterometer & Period & Cycle & Frequency & Agency \\
\hline \multirow[t]{5}{*}{ ERS-1 } & $\begin{array}{l}\text { Aug } 1991 \text { - } \\
\text { Mar } 1992\end{array}$ & 3 days & $\begin{array}{l}\text { C-band } \\
(5.3 \mathrm{GHz}, 5.7 \\
\mathrm{cm})\end{array}$ & ESA \\
\hline & $\begin{array}{l}\text { Apr } 1992- \\
\text { Dec } 1993\end{array}$ & 35 days & & \\
\hline & $\begin{array}{l}\text { Dec } 1993- \\
\text { Apr } 1994\end{array}$ & 3 days & & \\
\hline & $\begin{array}{l}\text { Apr } 1994- \\
\text { Mar } 1995\end{array}$ & 168 days & & \\
\hline & $\begin{array}{l}\text { Mar } 1995- \\
\text { May } 1996\end{array}$ & 35 days & & \\
\hline ERS-2 & $\begin{array}{l}\text { Apr } 1995- \\
\text { Jan } 2001\end{array}$ & 35 days & $\begin{array}{l}\text { C-band } \\
(5.3 \mathrm{GHz}, 5.7 \\
\mathrm{cm})\end{array}$ & ESA \\
\hline QuikSCAT & $\begin{array}{l}\text { Jul } 1999- \\
\text { Nov } 2009\end{array}$ & 4 days & $\begin{array}{l}\text { Ku-band } \\
(13.4 \mathrm{GHz}, \\
2.2 \mathrm{~cm})\end{array}$ & JPL \\
\hline ASCAT & $\begin{array}{l}\text { Oct } 2006- \\
\text { Present }\end{array}$ & 29 days & $\begin{array}{l}\text { C-band } \\
(5.3 \mathrm{GHz}, 5.7 \\
\mathrm{cm})\end{array}$ & EUMETSAT \\
\hline
\end{tabular}


Table 2: Statistical comparison results of collocated 6-hourly offshore NDBC, blended, and ERA-Interim 10m wind speed and direction. They are shown for the whole study period (1992 2012) and for ERS-1 (March 1992 - June 1996), ERS-2 (March 1996 - January 2001), QuikSCAT (July 1999 - November 2009), and ASCAT (March 2007 - March 2012) operating periods. Bias is defined as the mean difference between buoy and blended winds (in this order). Std, bs, $\stackrel{\boldsymbol{r}}{ }^{2}$, and $\boldsymbol{\boldsymbol { P }}$ indicate the standard deviation, regression symmetrical coefficient, scalar correlation coefficient, and vector correlation coefficient, respectively. The latter varies between -2 and +2 . Statistics that rely on comparisons between NDBC and ERA-Interim are shown within brackets.

\begin{tabular}{|c|c|c|c|c|c|c|c|}
\hline \multirow[b]{3}{*}{ Period } & \multicolumn{7}{|c|}{$8+$} \\
\hline & \multicolumn{4}{|l|}{ Wind Speed } & \multicolumn{3}{|c|}{ Wind Direction } \\
\hline & $\operatorname{Bias}(\mathrm{m} / \mathrm{s})$ & $\operatorname{STD}(\mathrm{m} / \mathrm{s})$ & bs & $r^{2}$ & Bias (deg) & $\begin{array}{l}\text { STD } \\
(\operatorname{deg})\end{array}$ & $\beta$ \\
\hline $1992-2012$ & $0.09(0.52)$ & $1.02(1.50)$ & $0.97(0.94)$ & $0.96(0.92)$ & $-6(-6)$ & $19(19)$ & $1.90(1.90)$ \\
\hline $1992-1996$ & $0.08(0.39)$ & $1.05(1.43)$ & $0.98(0.96)$ & $0.95(0.92)$ & $-8(-8)$ & $19(19)$ & $1.90(1.90)$ \\
\hline $1996-2001$ & $0.05(0.45)$ & $1.00(1.40)$ & $0.99(0.95)$ & $0.96(0.92)$ & $-9(-9)$ & $19(20)$ & $1.90(1.90)$ \\
\hline $1999-2009$ & $0.12(0.43)$ & $1.00(1.60)$ & $0.96(0.86)$ & $0.96(0.91)$ & $-5(-6)$ & $18(18)$ & $1.90(1.91)$ \\
\hline $2007-2012$ & $0.17(0.41)$ & $1.06(1.66)$ & $0.95(0.86)$ & $0.96(0.91)$ & $-3(-4)$ & $18(18)$ & $1.89(1.90)$ \\
\hline
\end{tabular}


Table 3: Same as Table 2 but for nearshore NDBC wind data.

\begin{tabular}{|c|c|c|c|c|c|c|c|}
\hline \multirow[b]{2}{*}{ Period } & \multicolumn{4}{|l|}{ Wind Speed } & \multicolumn{3}{|c|}{ Wind Direction } \\
\hline & Bias (m/s) & $\operatorname{STD}(\mathrm{m} / \mathrm{s})$ & bs & $r^{2}$ & Bias (deg) & STD (deg) & $\beta^{2}$ \\
\hline $1992-2012$ & $0.51(1.30)$ & $1.68(2.51)$ & $0.85(0.77)$ & $0.90(0.84)$ & $-9(-9)$ & $27(27)$ & 1.67 (1.68) \\
\hline $1992-1996$ & $0.74(1.31)$ & $1.82(2.49)$ & $0.83(0.76)$ & $0.89(0.83)$ & $-9(-9)$ & $27(27)$ & $1.66(1.66)$ \\
\hline $1996-2001$ & $0.62(1.25)$ & $1.74(2.47)$ & $0.84(0.76)$ & $0.90(0.84)$ & $-8(-12)$ & $27(28)$ & 1.69 (1.69) \\
\hline 1999 - 2009 & $0.43(1.32)$ & $1.60(2.52)$ & $0.86(0.77)$ & $0.91(0.84)$ & $-8(-8)$ & $27(27)$ & 1.68 (1.69) \\
\hline $2007-2012$ & $0.41(1.30)$ & $1.66(2.56)$ & $0.86(0.77)$ & $0.91(0.84)$ & $-6(-6)$ & $27(28)$ & 1.66 (1.67) \\
\hline
\end{tabular}


Table 4: Same as Table 2 but for tropical buoy data (TAO, PIRATA, RAMA). Statistics that rely on comparisons between buoy data and ERA-Interim are shown within brackets.

\begin{tabular}{|c|c|c|c|c|c|c|c|}
\hline & \multicolumn{4}{|l|}{ Wind Speed } & \multicolumn{3}{|c|}{ Wind Direction } \\
\hline Period & Bias (m/s) & STD (m/s) & bs & 2 & Bias (deg) & STD (deg) & 3 \\
\hline $1992-2012$ & $0.19(0.62)$ & $0.87(1.14)$ & $0.98(0.96)$ & $0.92(0.90)$ & $-1(0)$ & $15(16)$ & $1.75(1.74)$ \\
\hline $1992-1996$ & $0.38(0.79)$ & $0.89(1.13)$ & $1.00(0.94)$ & $0.93(0.93)$ & $-4(-4)$ & $14(14)$ & 1.79 (1.79) \\
\hline $1996-2001$ & $0.08(0.69)$ & $0.93(1.27)$ & $0.98(0.94)$ & $0.91(0.89)$ & $2(3)$ & $17(17)$ & $1.72(1.71)$ \\
\hline $1999-2009$ & $0.12(0.61)$ & $0.86(1.15)$ & $0.97(0.95)$ & $0.92(0.90)$ & $0(0)$ & $16(16)$ & $1.73(1.71)$ \\
\hline $2007-2012$ & $0.22(0.53)$ & $0.83(1.06)$ & $0.97(0.97)$ & $0.93(0.91)$ & $-1(-1)$ & $14(15)$ & $1.77(1.76)$ \\
\hline
\end{tabular}

